NBER WORKING PAPER SERIES

SOCIAL CONSTRUCTION OF TRUST

TO PROTECT IDEAS AND DATA IN

SPACE SCIENCE AND GEOPHYSICS

Lynne G. Zucker

Michael R. Darby

Working Paper 5373

\author{
NATIONAL BUREAU OF ECONOMIC RESEARCH \\ 1050 Massachusetts Avenue \\ Cambridge, MA 02138 \\ December 1995
}

This research has been supported in the Center for History of Physics at the American Institute of Physics (AIP) by the AIP, the Andrew W. Mellon Foundation, the National Historic Publications and Records Commission, and the National Science Foundation and in the NBER Research Program on Industrial Technology and Productivity by the Alfred P. Sloan Foundation. Zucker acknowledges the privileged access to the interview data while Sociological Consultant and member of the Working Group for the Study of Multi-Institutional Collaborations in Space Science and Geophysics of the AIP. Zucker and Darby are especially grateful for the guidance provided by Joan Warnow-Blewett and Spencer Weart of AIP, as well as that of the Working Group, throughout the development, analysis, and writing of our initial research findings (Zucker and Darby, 1995). Two members of our research team, Jeff Armstrong and Maximo Torero, also suggested revisions on earlier drafts of this paper that substantially improved it. We are indebted to the heroic efforts of Maximo Torero who conducted the analysis of the data under very difficult time constraints and also to the detailed and accurate coding of interview material by Richard Johnson, Richard Bernard, and Christine Beckman. This paper is part of the AIP research program and NBER's research program in Productivity. Any opinions expressed are those of the authors and not those of AIP or the National Bureau of Economic Research.

(C) 1995 by Lynne G. Zucker and Michael R. Darby. All rights reserved. Short sections of text, not to exceed two paragraphs, may be quoted without explicit permission provided that full credit, including $\mathbb{C}$ notice, is given to the source. 


\title{
SOCIAL CONSTRUCTION OF TRUST TO PROTECT IDEAS AND DATA IN SPACE SCIENCE AND GEOPHYSICS
}

\begin{abstract}
This paper applies a rational action/economic sociology approach to the central organizational theory question of whether action is embedded in pre-formed institutions that are relatively cheap in terms of time and energy, or to what extent action becomes embedded in newly constructed institutions that are more costly but perhaps better adapted to task goals. We develop a new model of the social construction of trust-producing social structure based on the initial endowment of this structure, the demand for it, and the cost of social construction. We test the model with data on construction of social structure in collaborations in space science and geophysics developed in a large number of interviews conducted by the Center for History of Physics of the American Institute of Physics. We do find that greater pre-existing endowment reduces social construction of new institutions while greater demand for trust increases that construction. We also find some evidence that social construction of trust-producing social structure in fact results in production of higher value science.
\end{abstract}

Lynne G. Zucker Department of Sociology University of California, Los Angeles Los Angeles, CA 90095-1551 and NBER
Michael R. Darby

Anderson Graduate School of Management University of California, Los Angeles

Los Angeles, CA 90095-1481

and NBER 


\title{
Social Construction of Trust to Protect Ideas and Data in Space Science and Geophysics ${ }^{1}$
}

\author{
Lynne G. Zucker \\ and \\ Michael R. Darby
}

Our central problem can be simply stated: Trust among scientists allows early sharing within a research collaboration or at least active use of ideas and the theoretical models and data they generate. The potentially high scientific value of these ideas, models, and data are often recognized before they can adequately be protected through publication, copyright, or patent. If scientists do not feel sufficiently protected, they may decide not to join the collaboration, they may move their best ideas and models out of the collaboration to another experiment, or in some extreme cases, they may even exit the collaboration after projects/experiments are underway. Trust, by protecting use of high value new ideas, tends to increase the overall value of the results of scientific collaboration.

The research collaborations we are studying can best be described as federations of

'Zucker is Professor of Sociology at UCLA and Director of the Organizational Research Program at the Institute for Social Science Research, UCLA. Darby is the Warren C. Cordner Professor of Money and Financial Markets and Director, John M. Olin Center for Policy, at the John E. Anderson Graduate School of Management, UCLA. Both are Research Associates of the National Bureau of Economic Research. This paper is part of both the AIP research program and the research program in Productivity at the NBER. Any opinions expressed are those of the authors and not those of AIP nor of NBER. 
separate scientific teams directed by different Principal Investigators (PIs). Figure 1 presents the 14 collaborations we are studying in space science and geophysics, outlining the areas of science and research topics covered (Joel Genuth 1995a and b; Lynne G. Zucker and Michael R. Darby 1995; Joan Warnow-Blewett and Spencer R. Weart 1995). The ambitious scientific goals and the sheer size and complexity of the undertaking in each collaboration certainly meet Weinberg's (1967) definition of "Big Science." Because the individual scientific teams are on-going groups that pre-date the larger collaboration and draw most of their members from the same university as the PI, they commonly have well developed internal structures that establish trust. But collaborations of multiple research teams drawn from different institutions do not. Only COCORP in Figure 1 has most PIs drawn from a single institution, its home university--Cornell.

Trust itself is a positive asset, and thus there appears to be no reason to suspect that trust-producing social structure would not be constructed to facilitate interaction and exchange in scientific collaborations. But in fact social construction of trust requires considerable redirection of human time and energy, and therefore incurs real costs (Zucker and Ita Kreft 1994; Zucker, Darby, Marilynn B. Brewer, and Yusheng Peng 1995). The benefits of trust must outweigh these costs in order for social construction to take place. As a result, trustproducing social structure is often constructed with considerable ambivalence; it is often a "last resort" because it decreases direct scientific productivity through redirection of time and energy, with offsetting productivity benefits not guaranteed. Trust construction is a risky business. Most scientists in our collaborations would agree.

To examine trust construction, we adopt a rational choice approach (James $\mathrm{S}$. Coleman 1990, Ch. 1 and Part V; Coleman 1986, 1993). Our model explicitly takes the cost-reducing 
properties of received institutional structure into account and analyzes the motivations for social construction of new institutional structure. Institutional stability and change are thus codetermined. The issue becomes not whether action is embedded in social structure (Mark Granovetter 1985), but whether action is embedded in pre-formed institutions that are relatively cheap in terms of human time and energy, or to what extent action becomes embedded in newly constructed institutions that are more costly.

We examine two major determinants of trust-producing social structure: group identity, shared characteristics, and administrative rules that exist prior to beginning a new scientific collaboration, or the endowed supply of trust-producing structure, and the characteristics of each collaboration such as the expected value of the science that increase or decrease the demand for trust-producing structure within the collaboration. Together, the endowed supply of and demand for trust-producing social structure, along with the cost of creating any additional forms of that structure, determine the amount of social construction of trust that will occur during the course of the collaboration.

Our model combines central concepts from the sociological literature on institutions, especially the identification of factors creating the endowed supply of trust, and basic concepts of price theory drawn from the economic literature to explicate the conditions under which new construction of trust-producing social structure will occur, to predict the amount of trust that will be constructed, and to explore the mechanisms of social construction. We develop a general model that we believe applies to the construction of social structure and institutions more generally, but we restrict our empirical test to trust-producing structure in space science and geophysics. ${ }^{2}$ To model trust-production in science, we examine the social structure and processes of scientific activity, especially following the lead of Harriet Zuckerman (1967; 
1970; 1977; see also Zuckerman and Robert Merton 1971).

Trust rests on the expectation that others will treat you fairly. Initial endowed trustproducing social structure is often governed by implicit or explicit "rules of the game" that are reasonably assumed to be legitimate by all interacting. Production of additional trust requires reciprocal intentionality: the trusted other will not act only in his or her narrow self-interest, but will take your interests into account before acting, and you will do the same (Zucker 1986:57-58; Harold Garfinkel 1963:190). Under such conditions, individuals become open to social influence from another individual or from a third party who intervenes to mediate (Zucker, Darby, Brewer, and Peng 1995). Certainty or predictability is not necessarily related to trust production, though it may tend to be associated with the endowed supply of trustproducing social structure that exists prior to interaction. ${ }^{3}$

Our paper is divided into three main sections. First, we outline our theoretical approach to predicting when trust-producing social structure will be constructed, how much of that structure will be produced, and what kinds of social structure will be used to create trust. We then draw examples from the 14 major collaborations in space science and geophysics, using information primarily drawn from interview transcripts to explore the relative roles of the endowed supply of and the demand for trust-producing social structure on the allocation of returns to the PIs, whether rule-based formal structures or collegial structures were formed, and how trust-producing social structure is related to high value of the science produced. In the third major section of our paper, we present a series of analyses using variables constructed from the interview data that provide strong support for our major conjectures. We conclude by examining the advantages of combining sociological and economic concepts to understand the development and use of trust-producing social structure. Implications for 
the organization of modern scientific collaborations are also considered.

\section{ENDOWED SUPPLY, DEMAND, AND COST: HOW MUCH TRUST-PRODUCING}

\section{SOCIAL STRUCTURE?}

Every social structure has its price. In our analysis of major collaborations in physics, we are focusing on the construction of new social structure, but it also takes human energy and time to maintain pre-existing social structure which would otherwise usually decay over time (Zucker 1977). We assume that for scientific teams the cost of constructing social structure must be balanced by enhanced ability to "get the job done, " since returns to scientists are determined largely by their scientific productivity. ${ }^{4}$

We identify trust-producing social structure, both pre-existing and socially constructed within the collaboration, as the major mechanism for allocating important scientific returns, including raw data, new discoveries, research articles, scientific citations to those articles, patents, and the like. A central premise is that the amount of initial trust-producing social structure varies significantly among social groups, especially task groups drawn from different sub-disciplines and universities that are brought together for specific purposes that may not align well with prior social structure, including multi-institutional and interdisciplinary differences that inherently require some bridging. ${ }^{5}$

To anchor the discussion of our model of trust production, we begin in Figure 2 by outlining the major variables operationalized in our research on collaborations in space science and geophysics. We cite the sources suggesting relevant empirical measures, or where empirical work has been scanty, the most relevant theoretical treatments. Our operational measures of the endowed supply emphasize the aspects of initial social structure that vary 
among the collaborations we are studying to determine whether different endowments alter production of trust-producing social structure, excluding aspects of the endowed supply such as broad scientific norms that we expect a priori to vary little between groups. Our operational measures of demand focus on those that are related to the attainment of major goals of our task-oriented scientific collaborations; when low levels of trust-producing structure would interfere with goal attainment, we argue that task-oriented groups will be highly motivated to create or borrow additional social structure to produce trust. The endowed supply of and demand for trust-producing social structure jointly determine how much social construction occurs, as measured by the social production of formal rules, collegial relations, and strong control rights by the PI during the collaboration.

All of our data, including our quantitative measures, derive from a three-stage analysis of 197 detailed interviews conducted with key participants from each of the 14 collaborations, primarily by historians and archivists from the Center for the Study of History of Physics at AIP. We address the most important methodological issues regarding our coding of these extensive interview transcripts, many of which are over 100 pages in length, at the beginning of Sections II and III; issues of sample selection and selection of number of interviews per collaboration are dealt with in the Appendix. Further detail on each of the measures outlined in Figure 2 are provided in Table 1 that appears at the beginning of Section III of this paper.

\section{Costs and Social Construction of Trust-Producing Social Structure}

The interaction of the endowed supply, the demand, and the cost of constructing trustproducing social structure will be shown below to determine how much social construction takes place in each collaboration. The cost conditions determine the gap between the 
endowed supply and the quantity demanded which is filled by newly constructed trustproducing social structure.

The initial level of trust in a collaboration is determined by the pre-existing social structure (on background expectancies, Alfred Schutz 1964:207-259 and Garfinkel 1963:190192; on framing, Erving Goffman 1974). We can think of this initial level of trust as due to the endowed supply of trust-producing social structure available at the beginning of a project. This endowment may be sufficient to provide initial guidance for allocation of project returns among members of a scientific collaboration. Our basic argument is this: Scientists differ in the degree to which they will form new social structure to produce trust during a collaboration as a function in part of the adequacy of the pre-existing social structure in producing trust.

In many task-groups, the endowment of trust-producing social structure would be difficult, if not impossible, to measure separately from construction of new trust-producing structure within the group because the origin of the group pre-dates any of the current members--not even retrospective accounts would be readily available. In contrast, our study of temporary collaborations has the advantage of relatively recent social origins and rich accounts, with an average of 14 respondents per collaboration, concentrated among the key scientific players including initiators, administrators, and PIs. ${ }^{6}$ Temporary collaborations have a second advantage over other types of social groups: they are characterized by more socially transparent "culture," and thus participants can "see" rich details of social structure and trust and communicate them well in the AIP interviews (Zucker 1977; Peter L. Berger and Thomas Luckmann 1966; on the AIP interviews, see Genuth 1995a and b, and Zucker and Darby 1995).

Trust may be constructed through formal means, by formula and rule, such as allowing 
PIs an extended "exclusive use" period during which data and analysis are considered proprietary (elsewhere called institutional-based or impersonal trust, Zucker 1986), and trust may also be constructed through informal mechanisms, involving highly personal social relations, such as developing collegial relations among project teams to create common consent over rights and easier resolution of conflicts over those rights (elsewhere called process-based trust, Zucker 1986). Both formal and informal bases may be part of the preexisting level of trust and also may be part of the social construction of new trust. Formation of trust-producing social structure, therefore, is not only possible, but routine; construction, however, occurs at the price of other activities foregone.

It is reasonable to assume that different kinds of trust-producing social structure alter the amount of trust in similar ways, so that a common metric is involved, and that they are generally additive. As we have argued, social construction of trust-producing social structure is a costly activity, and thus all else equal scientists prefer to join collaborations with higher initial endowments of social structure that produces trust. For example, bioscientists tend to limit their collaborations to within their organizational boundaries when the expected value of the science is high (Zucker, Darby, Brewer, and Peng 1995). But such choices also involve costs since the best personnel may not all be in the same organization, and a decision to not participate in one of the major space science or geophysics projects may entail sitting out the "only game in town."

The demand for trust-producing social structure depends not just upon the costs, but also upon both the incentives and opportunities for members of the group to act opportunistically. As the incentives are increased to act opportunistically, for example, due to higher expected value of the science to be produced, more trust-producing social structure is 
demanded both because any given amount produces less trust since the gains to others of opportunistic behavior are higher and because the losses to the scientist whose trust is abused are greater. We find in our analysis of the interview transcripts that expectations form early about the likely value of the science to be produced by the collaboration, based on how "smart" or successful key scientists are, the amount of resources available for the science, and, in one collaboration, the degree of success indicated by very early results obtained by that collaboration.

Besides incentives, opportunities for opportunistic behavior may be an important determinant of the demand for trust-producing social structure. The nature of the scientific tasks determine how appropriable the science being done is by other scientists, both by those within the collaboration and by those in the wider scientific community. Appropriability increases when PIs have access to others' data in the normal course of the project: Projects that require more coordination, such as use of shared vehicles including spacecraft in space science and ships in oceanography (geophysics), sometimes are not able to provide the same level of data compartmentalization. Also, less commonly, high levels of coordination may make clear allocation rules difficult because investments made by the PIs are sometimes not fully separable. Appropriability may, however, decrease if other scientists are not able to use the data because they are not able to interpret it adequately in the absence of detailed information on the instrument or direct collaboration with the Principal Investigator.

\section{The Model}

We now formulate a situational or short-period model of ad-hoc construction of trustproducing social structure specific to a particular scientific collaboration. This model explains 
social construction of trust-producing social structure in terms of the initial level of trust in the collaboration, the cost of social construction, and the demand for trust specific to the collaboration.

Figure 3 sketches the cost conditions underlying creation of additional units of trustproducing social structure. The horizontal axis measures the amount of social structure created (where the metric is thought of as proportional to the structure's effectiveness at producing trust) and the vertical axis measures the "marginal cost" of creating one additional unit of social structure given that the amount on the horizontal axis has already been created. ${ }^{8}$ The total cost of creating any amount $\mathrm{X}$ of social structure is thus the area under the marginal cost curve labeled $\mathrm{C}$ to the left of $\mathrm{X}$. The marginal cost will rise the more social structure is created since the least expensive methods of creating trust will be chosen first and more trust can be had only by using less and less effective means relative to the time required in constructing the social structure. We explicitly assume that task-oriented groups will adopt more effective trust-producing social structure first. Linearly rising marginal costs (and falling demand below) is assumed for expositional convenience only.

In Figure 4 we combine the initial endowment of trust-producing social structure with the marginal cost curve of constructing additional structure to describe the cost conditions for the total quantity of trust-producing social structure. Consider first a collaboration with a relatively low initial endowment $\mathrm{E}_{\mathrm{L}}$ : additional trust-producing social structure can be constructed at a rising cost indicated by reproducing the marginal cost curve from Figure 3 labeled here as $C_{L}$ to indicate that it originates from the low initial endowment $E_{L}$. Compare this to another collaboration which starts with initial endowment $E_{\mathrm{H}}$. Everything is the same except the marginal cost curve $C_{H}$ is shifted horizontally by the differences in initial 
endowments of trust-producing social structure $Q_{H}-Q_{L}$. Now consider any total quantity $Q$ of trust-producing social structure, initial endowment plus constructed. The marginal cost of one additional unit of trust-producing social structure will be higher for the low-endowment collaboration than for the high-endowment collaboration $\left[C_{L}(Q)\right.$ versus $C_{H}(Q)$ for point $G$ versus $\mathrm{F}]$.

We do not deal further in our analysis here with direct measures of the cost of construction of social structure, but assume that the primary cost is the time and attention it takes to construct trust-producing structure internally. This cost can be thought of in terms of other activities foregone, in other words as a temporary reduction in other kinds of productivity which are expected to be compensated for in beneficial effects of trust production on total scientific productivity of the collaboration in the long run.

The equilibrium total amount of trust-producing social structure is determined by the interaction of these cost conditions with the demand curve of the collaboration for trustproducing social structure in Figure 5. This demand curve plots the marginal benefit (in terms of expected value of the trust produced) of one additional unit of trust-producing social structure versus its quantity. Generally, the more trust-producing social structure which already exists through endowment or construction, the less will be the value of one more unit. The equilibrium total quantity $Q_{L}$ of trust-producing social structure for a low-endowment collaboration will be determined by the intersection $G$ of the demand curve $D$ with the cost curve $\mathrm{C}_{\mathrm{L}}$. At any point to the left of $\mathrm{G}$, the cost of constructing a little more structure is less than the associated additional benefit. At any point to the right of $\mathrm{G}$, the costs are greater than the benefits for additional social construction. Thus trust-producing social structure will tend to be constructed up to the quantity $Q_{L}$. Similarly, the equilibrium total quantity $Q_{H}$ for 
a high-endowment collaboration is determined by the intersection of $C_{H}$ and $D$ at $F$. Two important conclusions can be drawn from the graph: (a) The total quantity of trust-producing social structure is predicted to be higher for the high-endowment collaborations $\left(Q_{H}>Q_{D}\right)$. (b) However, the amount of trust-producing social structure constructed is less for the highthan low-endowment collaborations since $Q_{H}-Q_{L}$ is less than the horizontal shift in the cost curve $E_{H}-E_{L}$ so $Q_{L}-E_{L}>Q_{H}-E_{H}$.

In Figure 5 (and Figure 6 below), we assume that the demand curve for trustproducing social structure crosses the vertical line at $\mathrm{E}$ (the initial endowment) at a height greater than the marginal cost of social construction of the first additional unit of trustproducing social structure. If the intersection were lower -- or indeed the demand curve intersected the horizontal axis to the left of $\mathrm{E}$-- then we would have a corner solution in which we predict no social construction of additional trust-producing social structure. In a few of the later space experiments, there is some evidence -- in the form of griping about the overbureaucratization of NASA - that the demand curve may have intersected the horizontal axis to the left of E, but this may simply reflect the scientists' complaints about the cost of trust-producing social structure without noting its benefits. ${ }^{9}$

\section{Differences in Demand for Trust-Producing Social Structure}

Differences in the collaboration-specific demand for trust-producing social structure will also have predictable effects on the total and socially-constructed quantities of trustproducing social structure as illustrated in Figure 6. There the cost conditions of social construction are combined, as before, with the initial endowment $E$ to obtain the marginal cost curve $\mathrm{C}$ for trust-producing social structure. Here we will be comparing two collaborations 
which are identical in endowment but differ in demand conditions to determine the effect of those differences on the equilibrium. Suppose that the collaborations differ in terms of the expected value of the science to be derived; so trust will be more important where the scientists expect that they have more to protect. Then for any given cost of one more unit of trust-producing social structure, more will be desired for the high-value than for the low-value collaboration. This is indicated by the fact that $D_{H}$ lies to the right of $D_{L}$ in Figure 6 . In equilibrium at points $\mathrm{F}$ and $\mathrm{G}$ for the low- and high-demand collaborations, respectively, we see that the quantities of both total and socially-constructed trust-producing social structure will be higher for the high-demand case $\left(Q_{H}>Q_{L}\right.$ and $\left.Q_{H}-E>Q_{L}-E\right)$.

Qualifications to the Model

Of course, collaborations typically differ on more than a single factor affecting endowment of or demand for trust-producing social structure. While this means that we cannot come to a definite a priori theoretical prediction on the effects of differences where they are in offsetting directions, it presents no real problem in our empirical analysis in Section III where we estimate the coefficients on measures of a number of variables affecting either endowed supply of or demand for trust-producing social structure.

A more significant limitation of the model is its situational or short-period nature. While this is generally appropriate for the scientific collaborations we are considering, when we think of longer-term, ongoing collaborations or series of collaborations or more generally of social construction of trust-producing social structure for, say, an entire profession, we would have to generalize the model considerably in ways that are beyond the scope of the current paper. For example, we will see that absence of shared socialization where 
collaborations are cross-specialization implies that collaborations must bear the additional costs of ad-hoc social construction. If such collaborations involve high-valued science and occur frequently over a professional's career, we would expect that common socialization would arise in graduate school to reduce the need for ad-hoc construction as a substitute. Thus, the endowed supply of trust-producing social structure may not be strictly independent of the factors affecting its demand. ${ }^{10}$ Expanding the model to consider such long-run/shortrun differences is left to future research.

\section{TRUST-PRODUCING SOCIAL STRUCTURE: QUALITATIVE ANALYSIS}

We have constructed a novel model of trust, and explained in part how collaborations in space science and geophysics fit this model. In outline, the model predicts that collaborations initially vary in the amount of endowed trust-producing social structure depending on common culture; if cultural heterogeneity cannot be walled off by segmenting teams or by segmenting tasks, that is if coordination and joint action is required, then demand is created for construction of trust-producing social structure and that demand is further increased as a function of the expected value of the science to be produced; trust-producing social structure includes both developing formal rules and building informal relationships, and since these structures are costly to produce, they are produced only under sufficient demand; the value of the science actually produced is significantly affected by the total amount of trust-producing social structure in the collaboration including both the endowed and socially constructed social structure.

We base our qualitative analysis on detailed reading and analysis of each of the 197 interviews from the 14 major collaborations, with scientific activities as outlined in Figure 2 
above, combined with existing archival data and secondary sources on all collaborations. The interviews, in both tape and typed manuscript form, are archived in the Niels Bohr Library at the American Institute of Physics in College Park, Maryland, along with all other records related to the space science and geophysics project which is Phase II of the Study of MultiInstitutional Collaborations. Both the interviews and related records are available upon application to qualified researchers, and will be documented in the next archival collections guide (see Niels Bohr Library 1994, p. 9, for the corresponding documentation for the Phase I Oral History Interviews).

We conducted four stages of analysis in all, two of which preceded the qualitative work; we will discuss the other two stages when we present our quantitative work in the next section of this paper. In the first stage, initial content coding of each interview was done, using a coding format developed iteratively by two independent coders across ten of the interviews drawn from different collaborations in both space science and geophysics. The coding format drew out specific areas, such as rules regarding data access and the type of authority exercised in each collaboration. In addition, each interview was also examined for information concerning the organization of the collaboration; based on what each respondent said about how the collaboration was organized, our coders created an organization chart designed to reflect how each scientist perceived the collaboration. Sometimes that chart describes the overall collaboration, while in other cases, the organization of government sponsors or of the PI's own project is described; thus, we have a phenomenological view from nearly every scientist of how the collaboration was organized. ${ }^{11}$

In the second stage more global information on the collaborations was coded.

Specifically, we combined information directly taken from the interviews, from the individual- 
level coding, from the organization chart, and from archival and background materials on each collaboration both collected by AIP and obtained from university and government archives, to create an overall coding of each collaboration, at the level of the entire collaboration. Variables coded include number of countries involved, institutional project scope--both lead institutions and all other institutions mentioned at some point in the individual-level interviews, sources of funding at the collaboration level, whether instruments were newly developed or not and what they were, vehicles used, data sharing from the collaboration perspective, the time period of the collaboration--initiation, funding, data collection, and end, authority type and general authority relationships, coordination, conflict, and collaboration history.

Of course, all of these projects operate in a broad common culture defining in outline how science is done, what is "good physics" (evaluation standards), and what kind of team organizations are "reasonable." But within that broad umbrella, there is enormous variance. We now turn to a discussion of some of the major dimensions along which these collaborations can be compared and contrasted, while at the same time providing some of the details of scientific activity taking place within five of these collaborations to provide a richer framework within which to interpret the quantitative results.

Prior Social Structure: Low Trust Construction

One project high in prior social structure imported into the teams is COCORP (Consortium for Continental Reflection Profiling). The subdisciplines of those interviewed were either identical or very similar. Although four institutions were actively involved, with eight on the Planning Committee, our respondents outside of Cornell pointed out, somewhat 
heatedly, that while data was technically available to everyone, it was in fact held pretty close. Because Cornell did the data processing "the sharing of the interpretational effort [with outside scientists] was superficial."

Cornell management was characterized as "executive style" to "autocratic, "but also viewed as run generally in a fair way with "decisions based on scientific merit" and "democratic in its politics" at the subproject level, principally because the "senior officers had more technical expertise than the junior ones." While COCORP cleverly built on expertise developed in oil exploration to obtain measurements relatively inexpensively by renting equipment from oil companies, and was expected to produce interesting deep structure results, it was not viewed as likely to lead to a major scientific breakthrough.

With strong prior social structure imported into COCORP, strong central administration, and findings expected to add to normal science primarily by incrementally adding to deep structure models, we expected and found few rules and few conflicts over proprietary rights to data. The actual results were unevenly characterized by our respondents from primarily important for the "quantity of the data received" (our emphasis) to "changing how geologists think about crustal geometry and evolution."

\section{Very Striking Discoveries Expected: High Trust Construction}

The astrophysics community is a tight knit one (see Preston 1987), but in the case of the Einstein Observatory (HEAO-2) collaboration the initial strong physics, instead of astronomy, leadership structure and the high expected value of discoveries may have led to early development of rules regarding data sharing within the collaboration. While many of the physicists worked in collaboration with astronomers, one physicist pointedly commented: 
"Astrophysics is too important to be left to the astronomers." Not only were there the usual sub-discipline and discipline-based differences in scientific framework, there was also some open challenging of disciplinary paradigms.

Taken as a whole, the level of dispute over rights to data was unprecedented--and the development of explicit rules began well before Einstein's launch. The Red Book, produced by the collaboration to divide the best 1000 "target" observations, was the product of heated negotiation within the collaboration over who was entitled to observe which part of the sky. It also laid out observing rights for the first year, establishing principles such as duplicative observations would not be made and dividing up observing time among the consortium members. One respondent noted that the project "began as a purely PI Class mission, and there were percentages the data was divided up ...40 percent for SAO [Harvard-Smithsonian Astrophysical Observatory], 25 percent for MIT and Goddard, 10 percent for Columbia." Gossip spread in the scientific community about the Red Book and the "blatant claim staking" by the PIs "inspired community measures to break the data monopoly."

There are two divergent views among our respondents about what happened next. One view is that the PI and other consortium members wanted to run this "as an observatory for the public good" and thus opened the collaboration to a guest observer program immediately and to full data access after one year. The more common view among our interviewees is that community pressure after the Red Book was made public forced the guest observer program and that data access remains partial and selective (only "good data or the clean data" ... "a small fraction of all the photons collected").

With high expected scientific value, it is not surprising that Einstein experienced conflict among the collaborators over proprietary rights to the data even before launch. But 
the amount of conflict generated by the larger outside astrophysics community was unprecedented, causing major changes in rules governing data access and especially access to observatory time, creating the guest observer program.

Despite the conflict, rules that worked for the collaboration were established, though improved collegial relations proved harder to come by with conflicts continuing into data analysis, especially between SAO and Columbia. Still, perhaps due in part to the formal rules that came to be accepted by all of the participants, the actual success of Einstein was as expected: one key respondent said "it made X-ray astronomy relevant to all fields and all disciplines of study [in astronomy], "while another emphasized that the "range of topics was enormous," and still another key respondent felt that it "changed astronomy's definition of what needed to be researched." Over 80 dissertations were produced from the observations according to one of the scientists. Many major discoveries were made, but the comment made by one participant in the face of much conflict and little collaboration among the four principal institutions really says it best: "Wouldn't trade the experience for a minute."

Subdiscipline Diversity: High Trust Construction

Two projects exemplify this type of collaboration well: WCR (Warm Core Rings) and WOCE (World Ocean Circulation Experiment). We will also briefly discuss Voyager, since it also included a wide range of subdisciplines, but did not occasion nearly the same level of social construction as did WCR and WOCE. The strong oversight by NASA of Voyager undoubtedly played a major role, as did low levels of required coordination across subprojects (other than that conducted by NASA).

The subdisciplines on WCR ranged across chemical, physical, and biological 
oceanography, and the instruments interfered with each other, requiring a strict limit on the number of instruments over the side of the ship at one time. A number of respondents reported conflict over this, which strongly limited observation time. There were also reports of major conflicts over data interpretation, and no monitoring of discrepancies nor attempts to reconcile them. While a number of the scientists reported reasonable success for their specific projects, overall the assessment was "no outstanding single results."

WOCE was even more ambitious in terms of the diversity of the disciplines brought together on shipboard, and at the same time judged even less ambitious with regard to the quality of the proposed science. There was marked conflict over gathering samples between physical and chemical oceanographers, and the chemical group felt that they lost. On most cruises, the chief scientists was a physical oceanographer--the final arbiter on which instruments went over the side of the ship was thus a partisan participant in the interdisciplinary wars over resource allocation. There were also a number of disputes about data sharing: "data collectors didn't want to share with modelers" and WOCE "lost the modelling community." There were many rules for data sharing, but these were routinely ignored, as were archiving requirements.

WOCE data was also not judged to be exceptionally valuable by the oceanographers participating in the collaboration. One respondent stated that WOCE was "not designed to find earthshaking new technology," and it is "unbelievably routine." A major criticism was a lack of support for data analysis; only data collection was supported financially. One respondent noted that he would never commit himself totally to WOCE, but was simultaneously working on 4 or 5 other projects. Another respondent noted that the project helps keep his lab going, but he is not doing significantly more science than he would have 
done without it.

Although the Voyager project also started out with a very diverse set of subdisciplines, intermediate between WOCE and WCR, just one basic rule regarding proprietary use was reported, and reports indicated generally good cooperation across teams and little conflict (conflict reported only between one team and the astrophysicists). Most conflict related to competition (teams were described as "both competitive and collegial").

What accounted for the low conflict over data rights, given the subdiscipline diversity and the strong expectation of valuable results? Perhaps the directive NASA leadership through JPL, sometimes viewed by the scientists as "autocratic, "provided the overall social framework. Specifically, scientists on the Science Working Group (SWG) for Voyager chose to limit their scope, and thus maximize their autonomy from each other; at the same time, this increased the role of the NASA Project Manager in determining such aspects as the location and shielding of the instruments from each other. ${ }^{12}$

Largely through the administrative strategies of NASA, data ownership and other resource allocation issues did not arise as major barriers to high scientific performance in Voyager despite the relatively diverse sub-disciplines involved, need to coordinate across instruments both in design and data collection, and the strong expectations of success for the mission. One respondent noted that the "proprietary concerns across the experiments were very high, for the obvious reasons that each team invested large efforts in instrument design and basic data processing." Competition was judged high both within and between teams, but the collegial atmosphere was still maintained in most instances, with sub-groups cooperative between the plasma and magnetometer team and a little more rivalry between the cosmic ray and low energy teams--but this was viewed as "constructive" rivalry. Overall, the trust- 
producing role of the NASA administrators protected the science: results were judged "spectacular," "a scientific tour-de-force." Many important discoveries were made that increased scientific understanding of the outer solar system. One respondent reported that Voyager was the highlight of his life, another stated that it was his most enjoyable project.

We cannot adequately unravel these relationships in a single taxonomy or typology, because we expect that more than one factor affects how much construction of trust-producing social structure actually takes place in a collaboration. So we now turn to a multivariate analysis, where we can enter a number of different variables into our analysis at one time. Given the wide variance we have depicted in our qualitative analysis, plus the many variables with only one case that differs, such as the role of the outside scientific community in Einstein, the fact that we are still able to explain much of the variance in the construction of trust-producing social structure across the 14 major collaborations lends greater support to our conjectures regarding the conditions under which such construction occurs. We also examine the relation of trust-producing social structure to the eventual success of the collaboration, understanding that we did not have measures of many of the main variables that underlie success, such as prior scientific work by each P.I. and total amount of resources devoted to the collaboration. As one key scientist in Voyager noted: "What makes a mission successful is the people and their commitment and attention to detail."

\section{TRUST-PRODUCING SOCIAL STRUCTURE: QUANTITATIVE ANALYSIS}

We have already outlined the two stages of our analysis of interview materials that preceded our qualitative analysis, so we now turn to the remaining two stages that preceded our quantitative work. The third stage involved coding in quantitative form the variables 
already identified in the first stage of our coding. Salient points from each interview coding form that represented an individual scientist's or administrator's experience in the collaboration were transcribed in reduced form, including the employing organization, the self-reported discipline, Ph.D. year and university, role on project, report of prior or post contact with collaboration members, the instrument designed/built/used, who was responsible, and where it was built. Source of funding, data sharing, why joined collaboration, expected success of collaboration, actual success of collaboration, individual contribution to that success, the measure(s) of success, and finally the number and type of meetings held rounded out the reduced coding done of the individual interviews. We assigned a number to each person interviewed to maintain anonymity, in line with the decision not to identify individual respondents in publications.

Second, the organization chart was quantified by combining the phenomenological perceptions of organization and hierarchy across scientists in the same collaboration.

Sometimes these perceptions are quite similar, sometimes divergent. Specifically, to be able to use these measures of organization across different collaborations, we coded the number of countries, number of institutions, number of levels of the administrative hierarchy at its highest, the number of scientific review panels identified, the number of agencies/institutions involved in the review, and the number of subareas involved in the review, and whether the interviewee's primary focus was on the governmental level, the institutional level, or the level of the scientific group.

In our qualitative analysis, we were concerned with general correspondence between our model of trust-producing social structure and the scientific activities and events that took place in the collaborations. In this section we turn to somewhat tighter specification of the 
variables and models along the main dimensions of our model; even tighter and more systematic tests will have to await collection of data specifically for that purpose. In Table 1 we introduce the variables used in our analysis which are defined in Table 2. Most of the variables that we constructed specifically to test our model are presented in Tables 1 and $2 .^{13}$ In Table 1 the means and variance of the key variables in our analysis are reported separately for space science and geophysics, and we test for significant t-statistics for both this difference and for the difference between the two sub-groups within geophysics, climatology/tectonics and oceanography controlling for unequal numbers of cases.

Under measures of the Initial Endowment of each collaboration, we do find some significant differences between the major science groupings as well as sub-group differences within geophysics. Beginning with Cultural Homogeneity, only the tectonics/climatology differences from oceanography reach significance: the number of different disciplines is significantly higher in oceanography. Under Dispersion of Control, the number of government organizations involved is also significantly higher in oceanography. Under Concentration of Control, however, only the space science/geophysics comparison is significant: the NASA/NSF difference is of course expected, with NASA always involved in the large space science collaborations and with NSF never involved, compared to a strong role for NSF in the geophysics collaborations and a very minor one for NASA (mainly satellite tracking of ocean conditions and satellite weather data). Also interesting is the union of these sciences: the U.S. government is involved in funding and some degree of oversight of all fourteen collaborations. Under Organizational Homogeneity, the number of US institutes providing funding for collaborations is significantly higher in oceanography with no significant differences emerging overall between space science and geophysics. 
Under measures of Demand, however, we find a somewhat stronger pattern of differences between the sciences, with little evidence of significant differences within geophysics. Under Disruption of Trust, pre-publication required review occurs within geophysics collaborations only. Under Coordination--Joint Action, a significantly higher degree of coordination is required in space science as compared to geophysics, and in oceanography compared to climate/tectonics. Space science is also significantly more likely to have collaborations that involve constructing a scientific instrument across national boundaries that requires additional coordination among the scientists and engineers. Under Expected Scientific Value, space science collaborations have a higher expected scientific payoff on both measures--join experiment for high-value science and instrument exciting design--when compared to geophysics collaborations.

Under measures of the Construction of TPSS (TPSS translates as "Trust-Producing Social Structure"), we find significantly higher collegiality in oceanography compared to climate/tectonics and significantly stronger PI control rights (exclusive use of data in excess of 12 months) in geophysics as compared to space science. Possibly geophysics is "overprotecting, " often giving excessively long periods for analysis--sometimes because of lack of funding for the analysis stage--and thus possibly diminishing the overall productivity of the collaboration.

On our measure of the Value of the Science Produced we find that space science is significantly higher than geophysics. There are several alternative explanations, including that the year funding began (Control Variables) is significantly earlier for space science, with the mean slightly over ten years earlier. It is arguable that collaborations in geophysics, then, have not had the same time period over which to payoff and the value of their contributions 
to be recognized; we will discuss this potential interpretation in more detail below.

Finally, under Selectively Check, we examine the number of AIP interviews per collaboration; though the mean number of interviews is slightly higher in space science (15.8) than in geophysics (12.8), there is no significant difference between or within the sciences. We explore this further in the Appendix to determine whether there is significant selectivity in interviewing across individual collaborations.

Since space science and geophysics have some interesting significant differences in mean values, we decided to retain the dummy variable throughout our regression analyses.

\section{Tests of Social Construction of Trust-Producing Social Structure}

Our strategy in these first tests of the model of social construction of trust-producing social structure is to identify three different forms of such structure constructed in some of the experiments and to see whether any of the endowment and demand variables in Table 1 are significant determinants of that construction in the direction hypothesized. We also enter the space science/geophysics dummy (variable 24) separately and in combination with the fundamental variables.

Table 3 reports the principal results for OLS regressions explaining the number of rules created by the collaborations with regard to data and publications. Model 1 has both the highest explanatory power and the most favorable results for our hypothesis as it applies to construction of formal rules: The more different disciplines in the collaboration, the less cultural homogeneity and with this lower endowment of trust-producing social structure, significantly more rules are constructed. Where scientists are joining collaborations primarily because of the high expected value of the results, the demand is greater and there is a 
(borderline) significant increase in the number of rules. The insignificant coefficient on variable 24 assures us that we are not just picking up a difference between standard practices in space science and geophysics.

We anticipated that the number of scientific review boards would also be a good indicator of lack of cultural homogeneity since it would seem to indicate that different groups were thought necessary to pick PIs in different areas, but this variable just lowered the explanatory power of Model 1 and the t-values of the other coefficients when added (Model 3). Since there was thus some indication of multicollinearity we tried dropping the insignificant variables from Model 3 in Model 2, but variable 2 remained insignificant. Finally, we report in this and the following tables a final baseline model with just the control variable 24 .

In Table 4 , we predict the extent of collegiality constructed by the collaboration. We find that the highest explanatory power of the regression occurs when the number of U.S. institutes providing funding is included, but inclusion of that variable 10 precludes any significant effects from any of the demand variables. We argue that private institute funding reduces the authority of NASA and/or NSF so that more trust-producing social structure in the form of collegiality is constructed. The number of different disciplines is again significant in the right direction as is the maximum number of levels of authority reported for the organization chart. Models 3 and 4 indicate that two other variables including one demand variable reach significance (also in the predicted direction) if entered separately with variable 7 ; however, the explanatory power is significantly reduced.

Table 5 reports the results for explaining the construction of more extreme versions of PI protective rules granting exclusive use of data for more than a year. Here the results were 
more mixed for the hypothesis: More different universities and institution of rules for prepublication review (primarily a flag for conflicting publications) both increase the probability that strong PI rights will be adopted; however, both NASA and the number of foreign sources of funding have the wrong signs, reaching borderline significance for the latter variable in Models 1 and 3. Since the negative sign on variable 11 might simply indicate differences between foreign and U.S. (particularly NASA?) practices with respect to data access, we do not want to over interpret these small-sample results.

Overall, we find that construction of both formal and informal forms of trustproducing social structure is increased in these space science and geophysics collaborations where the initial endowment of trust-producing social structure is lower. We find less robust support for the hypothesis that increases in demand for trust-producing social structure increases its construction. We expect that applying the model to other data sets with more predictable variation in the demand for trust-producing social structure will result in stronger evidence in support of that factor as well.

Effects on the Production of High-Valued Science

Our model assumes that social construction of trust-producing social structure is motivated by the positive effect of that effort upon scientific productivity. Thus, it seems appropriate to examine whether these data are consistent with that underlying assumption. We will do so, albeit with several significant caveats. First, we do not have comparable measures of the talent and energy of the scientists involved, including the quality of the initial ideas, such as ranking of proposals by peer review, though we would still lack a common metric across collaborations in different disciplines. It might be sufficient to have such measures 
only for the initiators of the collaboration: they develop the initial ideas, and if the collaboration is tightly focused, then the quality of these initial ideas may determine the overall success of the collaboration.

Second, we use measures of subjective success, as judged by individual scientists interviewed by AIP--both of their own research and the research of the collaboration as a whole. We do not have general measures of overall output, such as number of publications or, better, quality adjusted number of publications (taking into account citations to the research); but again validity of comparisons across areas of research, much less disciplines, is doubtful.

Finally, we do not have sufficient information about the resources provided to each scientist to develop and carry out a challenging research agenda. We note some specific mentions of underfunding in two geophysics collaborations, and in one the P.I. simply quit the project while in the other the P.I. delayed analyzing the data until, if, and when more resources were made available. Obstacles also included dividing up the resource pie among too many different investigators, for example, sometimes done in the interests of involving the entire research community in a very large scale project (e.g., WOCE): Then no one investigator may have the necessary resources to really do the science right.

Despite these caveats, in Table 6 we make a first step with the limited data available at measuring whether the social construction of trust-producing social structure actually increases the probability that the collaboration will produce high-valued science. Variables 4 (the number of government lead organizations) and 25 (the year funding began) serve as the key variables predicting high-valued science in the absence of social construction of trustproducing social structure. Model 1 includes these variables, the space science/geophysics 
dummy, and the three measures of social construction. Insignificant variables are successively dropped in Models 2, 3, and 4, but none achieves the explanatory power of Model 1. The only form of socially constructed trust-producing social structure which appears to contribute to predicting high-valued science in this data set is the number of rules regarding data and publications. While we have concerns about the adequacy of our data (and indeed any nonexperimental data), the sign and significance on variable 20 is consistent with the basic model in which these rules do contribute to the net productivity of the scientists in the collaboration despite the time invested in their construction.

\section{CONCLUSIONS}

Our access to detailed interviews and archival data on 14 major collaborations in space science and geophysics provides an excellent basis for testing ideas concerning social construction of trust-producing structure, allowing endowed supply of such structure to be taken into account as a result of the temporary or "ephemeral" status of these scientific collaborations. At the same time, data on these collaborations was collected for very different purposes, and hence does not provide even coverage of the major dimensions of our theoretical approach. We briefly review the main tenets of our model of the construction of trust-producing social structure and consider the advantages of an interdisciplinary approach. We then turn to a brief summary and review of our qualitative and quantitative results.

Advantages of Interdisciplinary Models of the Social Construction of Trust

In Section I we developed a simple model of the interaction of endowed supply of, demand for, and construction cost of trust-producing social structure, to explain the quantity 
of this structure constructed in situational or short-run scientific collaborations. This model combines insights and analytic frameworks drawn from sociology, psychology, and economics. Each of these disciplines has its own literature on how actors/individuals/agents interact when confronted with a social dilemma in which expectations of opportunistic behavior by the other actors have the potential of interfering with joint or team production which has the potential to leave all of the parties better off.

Sociology and psychology have focussed on trust as part of a broader social structure that, among other functions, determines how returns to scientific collaborations are allocated among the principals, here the Principal Investigators (PIs) and their teams. Alignment of initial expectations is indicated by the degree of homogeneity in scientific background (relatively small number of subdisciplines on the collaboration, small number of separate scientific review panels) and the degree of homogeneity in organizational membership (few organizations, so relatively strong group identity). We can think of these indicators as resonating with characteristic-based trust in sociology (Zucker 1986; more typically ethnic or gender characteristics, e.g., Clifford Geertz 1978) and social group identity in social psychology that creates in-group trust (Brewer and Roderick M. Kramer 1986; Brewer and Sherry Schneider 1990).

Economists have tended to analyze the same problems in terms of information asymmetries in which, besides repeated-games solutions, more reliance is placed on creation of market structures which support transactions in the face of potential opportunistic behavior (e.g., Darby and John R. Lott, Jr., 1989 and Darby and Karni 1973 on reputation and brand names or Klein, Crawford, and Alchian 1978 on vertical integration). In our analysis, initial administrative rules concerning property rights, primarily within NASA, was seen to also 
yield homogeneity of expectations related to trust as well as third-party enforcement of breaches of these expectations.

In our reformulation in this paper, we bring the two perspectives together and using tools from both sociology and economics, we formalize a theory of social construction that rests on concepts central to price theory: supply, demand, and (implicitly) cost. We also began the process needed to relate trust-producing social structure specifically to productivity, and presented an initial exploration of the positive effects of construction of formal structure (rules) on the production of high value science.

Qualitative and Quantitative Results: A Review

The qualitative analysis of collaborations in both space science and geophysics provided strong intuitive support for our model, including the effects of both endowed trustproducing social structure and demand for that structure on the social construction of additional trust-producing structure within each collaboration. There was also considerable anecdotal evidence for a causal relation between the amount of trust-producing social structure and the later production of high value science, though other variables for which we did not have data--such as differences in the productivity of associated scientists--also played major roles.

Our quantitative results are also very suggestive, showing an overall pattern of support for our major conjectures; results are generally in the right direction, though when they reach significance it is sometimes barely there. Still, we do have some very significant predicted relations, and when the full equation is examined, the overall results are often quite strong. At this point, we do not want to overgeneralize on the basis of fourteen collaborations and 
data which were primarily gathered for other purposes. In particular, we feel more comfortable with inferring the existence of significant relationships which we were able to uncover with such few cases than with inferring the nonexistence of statistically nonsignificant relationships. That caveat aside, we did find some interesting results.

Social construction occurs during the collaborations, while conditioned importantly by pre-existing social structure: the rules are newly created, not part of a pre-existing professional canon, and collegiality is a function of teamwork on these particular collaborations, not based primarily on prior interaction or collaboration. Creation of formal rules on data and publications was conditioned slightly on the expectation of high-valued science worth protecting, and more dramatically on measures of endowed cultural heterogeneity. In considering collegiality, we found evidence that administrative-based trust crowds out the production of informal mechanisms. For both rules and collegiality, there was some evidence that pre-existing trust-creating structure obviated further construction of trust mechanisms during the collaboration.

In addition, formal rules entered significantly among predictors of high-valued science. Thus, at least formal trust-creating mechanisms constructed during the collaboration appeared to have functional value by enhancing the actual value of the science produced. Social protection of intellectual property adds a significant increment to the eventual success of a collaboration, though clearly not it is not the only factor. Based in part on results from other research, we believe it is unlikely to ever overshadow the quality of the scientists who make up the collaboration (Zucker, Darby, and Brewer 1994; Zucker, Darby, and Jeff Armstrong 1994).

In sum, we use our model and its qualitative and quantitative tests to address a set of 
important issues that have received scant empirical attention prior to our research. Our measurement of key variables related to separating social embeddedness into endowed and situationally constructed structures, as well as our concern with the effects of these structures on group productivity, should spur other interested researchers to begin more systematic empirical investigation of these topics.

\section{APPENDIX}

Context of Our Study of Collaborations

The study of multi-institutional collaborations was initiated by Joan Warnow-Blewett, together with Spencer Weart, both of the Center for History of Physics, American Institute of Physics, in order to understand better how large-scale collaborations are organized, their special problems and benefits to physicists and to physics, and how these collaborations differ across different arenas of scientific investigation. Much discussion has developed around "Big Science, " but little empirical research has actually investigated how it is organized and what precisely are the consequences of large, multi-institutional collaborations for the science that gets done.

The initial study was of collaborations in High Energy Physics (HEP) by the Center for History of Physics of the American Institute of Physics (Warnow-Blewett and Weart 1992; Warnow-Blewett, Maloney, and Nilan 1992; Sisk, Maloney, and Warnow-Blewett 1992; Genuth, Galison, Krige, Nebeker, and Maloney 1992); the basic research design was modified and then extended to the study of collaborations in space science and geophysics. Our sociological team also produced a preliminary report to the American Institute of Physics (Zucker 1993). Extensive records related to this research project, including the original 
interview tapes and transcripts, are now archived and available to qualified researchers at the Niels Bohr Library (1994).

At the beginning of this new phase of research, in consultation with the AIP Working Group on Documenting Multi-Institutional Collaborations in Space Science and Geophysics, it was decided not to compare HEP directly to space science and geophysics, but rather to study the two new areas independently. More specific detail concerning the collaborations studied in the AIP project on space science and geophysics can be found in the report of the project historian, Dr. Joel Genuth (1995a, 1995b).

Selecting Collaborations and Selectivity Checks of Interview Data Specific collaborations were selected by AIP staff in consultation with the AIP Working Group on Documenting Multi-Institutional Collaborations in Space Science and Geophysics. Selection of scientists and managers/administrators to interview was also done in consultation with the Working Group and was also affected by availability of key personnel. In one case, death prevented interviewing an initiator of a collaboration; in other cases, travel schedules didn't mesh. Overall, though, most of the targeted interviews that were screened to be most important were actually completed.

Number of interviews per collaboration was more interactively determined. Not only was the availability of key persons important, but also for several collaborations there was a decision that further interviews were very unlikely to produce more information.

Our research team, funded principally by AIP but also by NBER, coded and fully analyzed a total of 197 interviews, 95 in space science across 6 collaborations, and 102 in geophysics across 8 collaborations. We also coded but did not analyze a small number of 
interviews for individual participants in related collaborations that either preceded the main collaboration of interest or were contemporaneous but involved different scientists. Two collaborations, both in geophysics, were affected by this decision. We did consider these interviews in our review of the overall collaboration, but felt that including aspects of a different collaboration in our measures of such variables as number of countries involved would be very misleading.

When we check for selectivity bias, including in the analysis only those 197 interviews fully coded and analyzed by the sociological team as discussed above, we find that it is reasonable to reject the hypothesis of bias. In Table A we report the results, showing six separate regressions.

The results indicate that, as might be expected, the number of all participating organizations (variable 8) most strongly predict the number of interviews, suggesting that a very sensible sampling procedure was used, given that the inter-institutional aspect of collaborations was identified during the planning stages of the project as among the most important variables. The number of different disciplines (or sub-disciplines) also shows a significant positive relationship to the number of interviews in Models 2 and 5, the only two in which it is entered. If the collaboration involves international instrument construction, the number of interviews is significantly higher in both Models 1 and 2; but the variable loses significance when the space science/geophysics control variable is entered in Models 4 and 5 . Space science does not differ significantly from geophysics in the total number of interviews. 


\section{REFERENCES}

Aghion, Philippe, and Jean Tirole. 1994. "The Management of Innovation." Quarterly Journal of Economics 109:1185-1209.

Berger, Peter L., and Thomas Luckmann. 1966. The Social Construction of Reality: A Treatise in the Sociology of Knowledge. New York: Doubleday.

Brewer, Marilynn B., and Roderick M. Kramer. 1986. "Choice Behavior in Social Dilemmas: Effects of Social Identity, Group Size, and Decision Framing. " Journal of Personality and Social Psychology 50:543-549.

Brewer, Marilynn B., and Sherry Schneider. 1990. "Social Identity and Social Dilemmas: A Double-Edged Sword." In Social Identity Theory: Constructive and Critical Advances, edited by D. Abrams and M. Hogg. Havester-Wheatsheaf.

Brewer, Marilynn B., and Madelyn Silver. 1978. "Ingroup Bias as a Function of Task Characteristics." European Journal of Social Psychology 8:393-400.

Coleman, James S. 1986. "Social Theory, Social Research, and a Theory of Action." American Journal of Sociology 91:1309-1335.

Coleman, James S. 1990. Foundations of Social Theory. Cambridge, MA: Harvard University Press.

Coleman, James S. 1993. "The Rational Reconstruction of Society: 1992 Presidential Address." American Sociological Review 58:1-15.

Darby, Michael R., and Edi Karni. 1973. "Free Competition and the Optimal Amount of Fraud." Journal of Law and Economics 16:67-88. 
Darby, Michael R., and John R. Lott, Jr. 1989. "Qualitative Information, Reputation, and Monopolistic Competition." International Review of Law and Economics 9:87-103.

DeSantis, Grace. 1980. "Realms of Expertise: A View from Within the Medical Profession." Pp. 179-236 in Research in the Sociology of Health Care, edited by Julius Roth. Greenwich, CN: JAI Press.

Eccles, Robert G. 1981. "The Quasi-Firm in the Construction Industry." Journal of Economic Behavior and Organization 2:335-357.

Eccles, Robert G., and Dwight B. Crane. 1988. Doing Deals: Investment Banks at Work. Boston, MA: Harvard Business School Press.

Eisenberg, Rebecca S. 1987. "Proprietary Rights and the Norms of Science in Biotechnology Research." Yale Law Journal 97:177-231.

Faulkner, Robert R., and Andy B. Anderson. 1987. "Short Term Projects and Emergent Careers: Evidence from Hollywood." American Journal of Sociology 92:879-909. Garfinkel, Harold. 1963. "A Conception of and Experiments with 'Trust' as a Condition of Stable Concerted Actions." Pp. 187-239 in Motivation and Social Interaction: Cognitive Determinants, edited by O.J. Harvey. New York: Ronald Press.

Geertz, Clifford. 1978. "The Bazaar Economy: Information and Search in Peasant Marketing." American Economic Review 68:28-32.

Genuth, Joel. 1995a. Report No. 2. Part A: Space Science. Section 2: HistoricalSociological Report. AIP Study of Multi-Institutional Collaborations, Phase II: Space Science and Geophysics. College Park, MD: Center for History of Physics, American Institute of Physics. 
Genuth, Joel. 1995b. Report No. 2. Part B; Geophysics and Oceanography. Section 2:

Historical-Sociological Report. AIP Study of Multi-Institutional Collaborations, Phase II: Space Science and Geophysics. College Park, MD: Center for History of Physics, American Institute of Physics.

Genuth, Joel, Peter Galison, John Krige, Frederik Nebeker, and Lynn Maloney. 1992. Report No. 4: Historical Findings on Collaborations in High-Energy Physics. AIP Study of Multi-Institutional Collaborations, Phase I: High-Energy Physics. New York: Center for History of Physics, American Institute of Physics.

Goffman, Erving. 1974. Frame Analysis. Cambridge, MA: Harvard University Press.

Granovetter, Mark. 1985. "Economic Action and Social Structure: A Theory of Embeddedness." American Journal of Sociology 91:481-510.

Kaufman, Herbert. 1960. The Forest Ranger: A Study in Administrative Behavior. Published for Resources for the Future, Inc. Baltimore, MD: The Johns Hopkins Press.

Klein, Benjamin. 1988. "Vertical Integration as Organizational Ownership: The Fisher Body-General Motors Relationship Revisited." Journal of Law. Economics, and Organization 4:199-213.

Klein, Benjamin, Robert Crawford, and Armen Alchian 1978. "Vertical Integration, Appropriable Rents, and the Competitive Contracting Process." Journal of Law and Economics 21:297-326.

Larson, Magali Sarfatti. 1977. The Rise of Professionalism: A Sociological Analysis. Berkeley, CA: University of California Press. 
Long, J. Scott, and Robert McGinnis. 1981. "Organizational Context and Scientific Productivity." American Sociological Review 46:422-442.

Nebeker, Frederik. 1995. Report No. 2, Appendix B: The Development of Very-BroadBand Seismography: Quanterra and the IRIS Collaboration. AIP Study of MultiInstitutional Collaborations, Phase II: Space Science and Geophysics. College Park, MD: Center for History of Physics, American Institute of Physics.

Niels Bohr Library. 1994. A Guide to the Archival Collections in the Niels Bohr Library at the American Institute of Physics. International Catalog of Sources for the History of Physics and Allied Sciences, Report No. 7. College Park, MD: Center for History of Physics, American Institute of Physics.

Preston, Robert G. 1987. First Light: The Search for the Edge of the Universe. New York: Atlantic Monthly Press.

Sayles, Leonard R., and Margaret K. Chandler. 1971. Managing Large Systems. New York: Harper \& Row.

Schutz, Alfred. 1964. Collected Papers II. The Hague: Martinus Nijhoff.

Sisk, Bridget, Lynn Maloney, and Joan Warnow-Blewett. 1992. Report No. 3: Catalog of Selected Historical Materials. AIP Study of Multi-Institutional Collaborations, Phase I: High-Energy Physics. New York: Center for History of Physics, American Institute of Physics.

Tolbert, Pamela S. 1988. "Institutional Sources of Organizational Culture in Major Law Firms." Pp. 101-113 in Institutional Patterns and Organizations: Culture and Environments, edited by Lynne G. Zucker. Cambridge, Mass.: Ballinger Publishing Co. 
Warnow-Blewett, Joan, Lynn Maloney, and Roxanne Nilan. 1992. Report No. 2:

Documenting Collaborations in High-Energy Physics. AIP Study of Multi-Institutional Collaborations, Phase I: High-Energy Physics. New York: Center for History of Physics, American Institute of Physics.

Warnow-Blewett, Joan, and Spencer R. Weart. 1992. Report No. 1: Summary of Project Activities and Findings/Project Recommendations. AIP Study of Multi-Institutional Collaborations, Phase I: High-Energy Physics. New York: Center for History of Physics, American Institute of Physics.

Warnow-Blewett, Joan, and Spencer R. Weart. 1995. Report No. 1: Summary of Project Activities and Findings/Recommendations. AIP Study of Multi-Institutional

Collaborations, Phase II: Space Science and Geophysics. College Park, MD: Center for History of Physics, American Institute of Physics.

Weinberg, A. M. 1967. Reflections on Big Science. Cambridge, MA: MIT Press.

Williamson, Oliver. 1979. "Transaction Cost Economics: The Governance of Contractual

Relations." Journal of Law and Economics 22:3-61.

Zucker, Lynne G. 1977. "The Role of Institutionalization in Cultural Persistence." American Sociological Review 42:726-743.

Zucker, Lynne G. 1986. "Production of Trust: Institutional Sources of Economic Structure, 1840 to $1920 .^{*}$ Research in Organizational Behavior 8:53-111.

Zucker, Lynne G. 1991. "Markets for Bureaucratic Authority and Control: Information Quality in Professions and Services." Research in the Sociology of Organizations 8:157-189. 
Zucker, Lynne G. 1993. "Detecting Patterns in High Energy Physics: Sociological Analysis of AIP Census and Focus Experiments." Report to the American Institute of Physics. New York: Center for History of Physics, American Institute of Physics.

Zucker, Lynne G., and Michael R. Darby. 1995. Report No. 2. Appendix A: Sociological Analysis of Multi-Institutional Collaborations in Space Science and Geophysics. AIP Study of Multi-Institutional Collaborations, Phase II: Space Science and Geophysics. College Park, MD: Center for History of Physics, American Institute of Physics.

Zucker, Lynne G., Michael R. Darby, and Jeff Armstrong. 1994. "Intellectual Capital and the Firm: The Technology of Geographically Localized Knowledge Spillovers. " Working Paper No. 4946. Cambridge, MA: National Bureau of Economic Research. Zucker, Lynne G., Michael R. Darby, and Marilynn B. Brewer. 1994. "Intellectual Capital and the Birth of U.S. Biotechnology Enterprises." Working Paper No. 4653. Cambridge, MA: National Bureau of Economic Research.

Zucker, Lynne G., Michael R. Darby, Marilynn B. Brewer, and Yusheng Peng. 1995 in press. "Collaboration Structure and Information Dilemmas in Biotechnology: Organizational Boundaries as Trust Production." In Trust in Organizations, edited by Roderick M. Kramer and Thomas Tyler. Newbury Park, CA: Sage Publications. Zucker, Lynne G., and Ita G. G. Kreft. 1994. "The Evolution of Socially Contingent Rational Action: Effects of Labor Strikes on Change in Union Founding in the 1880s." Pp. 294-313 in Evolutionary Dynamics of Organizations, edited by J. A. C. Baum and J. V. Singh. Oxford, UK: Oxford University Press.

Zuckerman, Harriet. 1967. "Nobel Laureates in Science: Patterns of Productivity, Collaboration, and Authorship." American Sociological Review 32:391-403. 
Zuckerman, Harriet. 1970. "Stratification in American Science." Sociological Inquiry 40:235-257.

Zuckerman, Harriet. 1977. Scientific Elite: Nobel Laureates in the United States. New York: Free Press.

Zuckerman, Harriet, and Robert Merton. 1971. "Patterns of Evaluation in Science:

Institutionalization, Structure, and Functions of the Referee System." Minerva 9:66100. 


\section{FOOTNOTES}

2. Social structure and institutions, including trust-producing structures, may therefore consist of two portions: one exogenous, formed prior to the situation and applied to it, and the other endogenous, constructed within the situation in response to demand.

3. Trust in social interaction is not the same as certainty or predictability of another's behavior, contra the Williamsonian (1979) argument. For example, a narcissistic individual will behave predictably in his or her self-interest. Much of his or her self-interested behavior both ignores the other person's interest and is not open to influence by the other person. Thus a narcissist's consistent behavior will at least disrupt trust, creating confusion, and in some cases will produce distrust, especially when the narcissist is thought to be acting intentionally contra one's interests (Zucker 1986:59).

4. Cost can be measured directly in terms of time and other resources spent; in examining scientists' careers longitudinally, it should be possible to identify periods of time at the beginning of major collaborations when productivity of the scientists falls because of their investment in creating trust-producing and other social structure (J. Scott Long and Robert McGinnis 1981 develop an excellent general approach to the study of productivity of scientists over their careers). In contrast, other elites for whom productivity may play only a small role if any in determining their returns would be more likely to value and to make heavy investments in maintaining social structure that identifies their position. Such elites maintain the local "green book" that identifies those who are "socially important" in the locality. For example, deposed royalty often get direct returns to their social position; since others of high status are presumed to value interacting with royalty, deposed royalty who no longer get direct support from the state live a life style that is out of reach of their personal 
income by being invited to charity events, political venues, and even on vacations (especially popular are ocean cruises) at others' expense, including those newly wealthy with less elite social backgrounds.

5. In our analysis of collaborations in High Energy Physics, we found that greater vertical integration of the science occurred (Zucker 1993). The primary mechanism was an increase in hiring physicists on staff by centralized accelerator centers. These Centers were sometimes able to hire the top physicists in the particle physics area who were then included on many of the collaborations involving scientists drawn from other universities.

6. Other social science research on temporary collaborations has focused primarily on decisions of whom to hire and thus on quality of labor issues (especially Robert R. Faulkner and Andy B. Anderson 1987 on projects in the film industry) or on the project-specific demand for certain mixes of labor in the construction industry, creating a "quasi-firm" in which subcontractors are differentially integrated into a firm depending on how frequently they are needed across different construction projects via negotiated contracts (no competitive bidding) and repeat contracts(Robert G. Eccles 1981:347).

7. When scientists were asked by AIP interviewers about their decisions to join collaborations, they responded most often in a mixture of expected scientific value and specific other persons already involved in the collaboration, coupling the desire to work on scientific projects that are likely to produce valuable science with a desire to work with other scientists who are trusted. Sometimes, of course the other scientists are desirable colleagues because they improve the odds of "hitting a home run."

8. The marginal cost is the derivative at $\mathrm{x}$ of the total cost of creating the $\mathrm{x}$ units of social structure. 
9. Not only may there be no additional construction, but scientists sometimes act to reduce the supply of endowed trust-producing social structure. For example, NASA's oversight structures produced trust in collaborations in the 1970s, but as these structures accreted over time, they may have interfered with scientific productivity without sufficient offsetting by additional trust. By the time of the AMPTE collaboration (funding in 1981, data in 1989), the Goddard Flight Center (managing for NASA) was judged by most scientists in AMPTE to be "excessively hierarchical" and "overmanaged, "with "lots of paperwork." The end result was that Goddard's oversight "created lots of friction between the project manager and the scientists" and the "formal and bureaucratic structure work[ed] contrary to success"; "NASA's coordination was too hands-on, they had layers of personnel double-checking all aspects of APL [Applied Physics Laboratory at Johns Hopkins] involvement and NASA wanted all communication between international teams to go through them." The scientists ended up circumventing Goddard, using "really strong international coordination by phone during data collection to get release timing right" and "eventually, the scientists took control." In order to produce good science, then, the scientists ignored the NASA/Goddard social structures designed to protect scientific decision-making and data access.

10. We do not attempt to deal with possible endogeneity of the endowed supply of trustproducing social structure with respect to demand variables in the empirical work both because we lack any plausible set of instruments and because we judge that such indirect effects on professional socialization via expectations of future collaborations are minimal for the periods and sciences with which we are dealing. We note, however, that long term processes of social construction often involve strategic use by administrators/managers of multiple mechanisms to create a common social frame. For example, a detailed study of the 
U.S. Forest Service revealed that at the same time the administrators created new formal trustproducing structures, in this case primarily formal rules that governed raises and promotions based on performance evaluation, they also simultaneously increased their requirements for prior professional training (endowed supply) and added in-service training for deliberate social construction via socialization (Herbert Kaufman 1960: Chapter VI).

11. One of our coders, Richard Johnson, coded nearly two-thirds of the interviews. Still, because three different coders were involved at various stages, we carefully checked intercoder reliability across five interviews, coding them independently three times. Inter-coder reliability was acceptably high and thus information is combined from all three coders in the analysis that follows.

12. While NASA management appears to have played a major role in resource allocation decisions on the Voyager collaboration, the scientists did create subcommittees to play an active role in taking first cuts at trajectory and orientation issues--these determined which investigators got data first, a crucial issue in the event of early mission failure.

13. The following variables were ones that did not enter significantly in any of our analyses though we had strong priors on them, expecting them to measure important dimensions of our theoretical model: number of countries involved (cultural homogeneity); vehicle(s) require coordination: 1 =yes, $0=$ no (coordination--joint action); and number of new instruments constructed (expected high scientific value). In the case of number of countries involved, we carefully re-read the interview transcripts to see if the scientists and administrators of these collaborations could help us understand why this variable did not significantly increase the social construction of trust-producing structure. One possible explanation is that there was very little collaboration across country boundaries. When the extent of collaboration across group boundaries can be measured more precisely prediction is generally improved (see for 
example Zucker, Darby, Brewer, and Peng 1995). For the variable "vehicles(s) require coordination," we discovered that NASA projects were most likely to require coordination and that they were also most likely to put project administrators in the position of providing that coordination. Adding interaction terms to our regression models might have provided a solution, but given the small sample size we decided not to explore interactions. Finally, it appears extremely difficult to measure initial expected high scientific value without also considering the choice set that each scientists had at the time. Our measure that codes why scientists joined the collaboration, ranging from personal ties to aspects of the scientific payoff, provides a stronger prediction. 
Table 1

Endowment, Demand, and Social Construction of Trust-Producing Social structure in Space Science and Geophysics

Variables

$\frac{\text { Spece Sci. }}{\text { Mean Var. }} \frac{\text { Geophysics }}{\text { Mean Var. Betw. Within }}$

\section{I.Initial Fndowment}

A.Cultural Homogeneity

1: \# dif. disciplines

2: \# scient. review bds.

7.00

6.80

$\begin{array}{lllll}6.62 & 10.84 & 0.23 & -2.91^{\mathrm{b}}\end{array}$

B.Oversight

0.45

0.14

1.31

$2.09-1.41-0.36$

1.Authority and Control Dispersion of Control

3: \# lead orgs.

4.83

6.57

3.1216 .70

$0.90-1.01$

4: \# govt. lead orgs.

1.83

1.37

1.00

1.71

$1.23-2.00^{\circ}$ Concentration of Control

$5:$ NASA, $y=1, n=0$

1.00

0.00

0.38

$0.272 .93^{b}-1.29$

6: NSF, $y=1, n=0$

0.00

0.00

0.88

$0.12-2.24^{b}-0.75$

7 : $\max$ levs. authority

7.67

3.47

7.50

$\begin{array}{lll}1.43 & 0.20 & 0.28\end{array}$

2. Org. Homogeneity

8: \# all orgs.

25.50

26.70

22.75

1.43

9: \# univs. in all orgs. 12.00

10: \# US institutes for \$

0.17

23.60

22.7579 .07

$0.67 \quad 0.40$

11: \# foreign \$ sources

2.50

0.17

14.50
0.13

30.57

$-0.88-0.06$

II. Demand

A.Disruption of Trust

12: pre-public. rev. , $y=1$

13 : conflict-data interp.

14: degree of conflict

5.50

0.75

0.13

$0.20-2.91^{b}$

B.Coordination-Jt. Action

15: shared vehicles 1.00

16 : deg. coordination req. 2.50

17: intl. instmnt. const. 0.67

0.00

0.00

0.50

1.93

$1.75-0.37$

C. Expected Sci. Value

18: join exp. hi-val sci.

19: instmnt. excit. des.

III.Construction of TPSS

20: \# rules re data,pubs.

21: collegiality

0.50

0.30

0.62

$0.29-2.27^{b}-0.65$

1.83

1.77

1.75

$0.27-0.44-0.16$

0.00

0.62

$\begin{array}{llll}1.64 & 0.12 & -1.80\end{array}$

1.90

0.75

0.27

$1.76-1.84$

0.27

0.00

0.50

$3.11^{c}-2.29^{a}$

2.33

1.07

1.25

0.00

$3.70^{\circ} \mathrm{n} / \mathrm{a}$

0.67

0.27

0.12

0.21

$2.66^{b}-0.37$

3.50

0.70

3.62

$0.122 .34^{b} 0.75$

22: strong PI control rts. 0.33

0.70

2.12

$3.12-0.16-1.37$

2.50
0.33

0.27

0.86

$0.980 .75-2.62^{b}$

IV.Value of Sci. Produced

23: high-val. science

0.67

$0.27 \quad 0.12$

$0.14-2.11^{\star}-0.85$

v.Control variables

24: space sci. 1; geoph.

25: year \$s began

vI.Selectivity Check

26: \# of AIP interviews $15.83 \quad 8.57 \quad 12.75 \quad 14.79 \quad 1.73 \quad-0.49$

Notes: Prob(|t-statistic| $>x): a<.1, b<.05, c<.01, d<.001$, based on 2-tailed test.

*t-stats are for differences between the reported means \& within geophysics between unreported means for climatology/tectonics and oceanography, assuming = vars. 
Table 2

List of Variables

No. Variable Description

1 \# of different disciplines as listed by interviewees re self

2 average \# of scientific review panels in organization chart

3 \# of institutions in "lead" role

4 \# of government institutions in "lead" role

5 NASA: $1=$ yes $; 0=$ no

6 NSF: $1=$ yes; $0=$ no

7 highest \# reported by any interviewee of levels of authority in organization chart

8 \# of all institutions involved including lead and all institutions coded as "home institution of PI or other collaborating scientist, subcontractors, other universities, research institutes, and government entities that contribute to the science being done"

$9 \quad$ \# of variable 8 institutions which are universities

10 \# of US institutions providing funding

11 \# of different foreign sources of funding

12

project has explicit rule re pre-publication review: $1=$ yes; $0=$ no

conflict over interpretation of data by others: $1=$ yes; $0=$ no

conflict $=$ sum of 4 categorical components: [reports of refusal to coauthor: $1=$ yes; $0=$ no] + [variable no. 13] + [other problems re data use: $1=$ yes; $0=$ no] $+[$ conflicts over authority:

$1=$ yes; $0=$ no]

15 shared vehicle(s): $1=$ yes $; 0=$ no

16 coordination $=$ sum of 4 categorical components: [vehicle(s) require coordination: $1=$ yes; $0=$ no] $+[$ instruments constructed across institutional boundaries: $1=y e s ; 0=$ no] $+[$ variable no.

17] + [analysis significantly involves coordinated data: $1=$ yes $; 0=$ no]

17 instruments constructed across national boundaries: $1=$ yes; $0=$ no

18 reason for joining the collaboration: 1 =personal contact; 2 =personalcontact \& science reason; $3=$ science reason emphasized

19 instruments characterized as having exciting design: $1=y e s ; 0=$ no

20 rules $=$ sum of 8 categorical components: [project has at least one explicit rule re data:

$1=$ yes $; 0=$ no $]+[$ PI has exclusive use period: $1=$ yes; $0=$ no $]+[$ archive in required location?:

$1=$ yes; $0=$ no] $+[$ coauthor rules explicit: $1=$ yes $; 0=$ no] $+[$ coauthor rules for initial publications:

$1=$ yes $; 0=$ no] + [required publication, e.g. if take samples: $1=$ yes; $0=$ no] + [rules re data

access: $1=$ yes $; 0=$ no] $+[$ rules re timing of publication (e.g., no publication before initial

volume): $1=$ yes $; 0=$ no]

21 collegiality $=$ sum of 3 categorical components: [oversight informal, empowering: $1=$ yes; $0=\mathrm{no}]+[$ science level informal, empowering: $1=$ yes; $0=\mathrm{no}]+[1$ if overall collaborative style characterized by partnership/collegiality, autonomy, self direction, respect for technical judgement, or most of the project collegial, part autocratic; 0 if characterized as autocratic/directive, little respect for technical judgement of others, or mostly autocratic, part collegial]

22 PIpriv $=1$ if PI has exclusive use period which at least in some cases exceeds 12 months, 0 otherwise

23 hivalsci $=1$ if respondents report "major discoveries," "interesting results," and either "major initial objectives reached and main scientific purpose realized" or "very important unexpected finding, " 0 otherwise

24 Science: Space Science $=1$, Geophysics $=2$

25 year funding began

26 \# of AIP interviews 
Table 3

Predictors of the Number of Rules

regarding Data and Publications

Dependent variable: 20--sum of 8 categorical variables ( 1 yes, 0 no) on whether various types of rules on data use and publications are created in the collaboration (see Table 2)

Ind. Variables

Modelg
Model 1 Model 2 Model 3 Model 4

Constant

$-0.462$

$1.574^{*}$

$-0.820$

$3.375^{b}$

(1.899)

$(0.771)$

$(2.600)$

$(1.294)$

ENDOWMIENT

cult. Homogen.

1: \# dif.

$0.308^{\circ}$

$0.240^{*}$

$0.283^{b}$

disciplns.

$(0.103)$

$(0.113)$

$(0.125)$

2: \# scient.

rev. bds.

0.388

$(0.280)$

0.149

$(0.389)$

\section{DEMAND}

Exp. Val. Sci.

18: join exp.

$0.751 *$

hi-val sci $(0.414)$

0.634

$(0.530)$

CONTROL VARS.

24: space sci

1 igeoph. $2(0.738)$

$\begin{array}{ccc}- & 0.790 & 0.125 \\ (1.037) & (0.785)\end{array}$

Adjusted $\mathbf{R}^{2}$

$0.40^{b}$

$0.38^{b}$

$0.35^{*}$

$-0.08$

Notes: Standard errors are in parentheses below coefficients. Prob (|t-statistic| $>x): a<.1, b<.05, c<.01, d<.001$. 


\section{Table 4 \\ Predictors of Collegiality}

Dependent variable: 21--sum of 3 categorical variables on whether collaboration developed an informal, collegial atmosphere

Ind. Variables

Models

Model 1 Model 2 Model 3 Model 4 Model 5

Constant
$4.333^{\circ}$
$3.717^{d}$
$4.115^{d}$
$4.407^{\circ}$
$2.875^{\mathrm{c}}$
$(0.725)$
$(0.924)$
(1.074)
$(0.827)$

ENDOWLENT

Cult. Homogen.

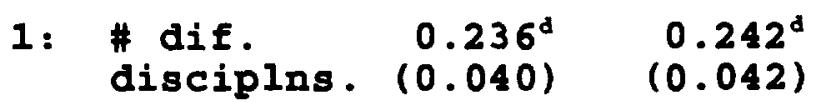

Disp. of Control

4: \# gov. lead orgs.

Conc. of Control

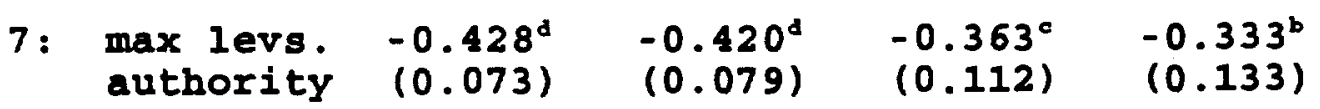

Org. Homogen.
10: \# U.S.
$0.706^{\star}$
$0.757^{b}$
instits.
$(0.318)$
$(0.340)$

\section{DEMAND}

Coordination

15: shared vehicles

CONTROL VARS.

24: space sci. -0.328

1;geoph. $2(0.205)$

Adjusted $\mathbf{R}^{2}$

$0.83^{d}$

$0.80^{d}$

$0.59^{c}$

$0.44^{b}$

$-0.375$

$(0.502)$

Notes: Standard errors are in parentheses below coefficients. Prob $(\mid t-$ statistic $\mid>x): a<.1, b<.05, c<.01, d<.001$. 
Table 5

Predictors of strong Principal Investigator Control Rights

Dependent variable: 22--1 if the PIs have an exclusive-use period for data and the maximum reported period exceeds 12 months; 0 otherwise

Ind. Variables

Models
Model 1 Model 2 Model 3 Model 4

Constant

$\begin{array}{llll}-0.807 & -1.017 & -0.102 & -0.190 \\ (0.514) & (0.673) & (0.272) & (0.402)\end{array}$

ENDOWMENT

Conc. of Control

$5: \quad \begin{aligned} & \text { NASA } \\ & n=0\end{aligned} \quad \begin{array}{cc}0.460 & 0.503 \\ (0.292) & (0.317)\end{array}$

Org. Homogen.
9: \# univs.
$0.078^{c}$
$0.078^{\mathrm{b}}$
$0.055^{b}$
in all
$(0.021)$
$(0.023)$
$(0.017)$

11: \# foreign $-0.089^{*} \quad-0.082 \quad-0.087^{*}$

$\begin{array}{llll}\text { sources } & (0.041) & (0.045) & (0.044)\end{array}$

\section{DEMAND}

Trust Disrupt.

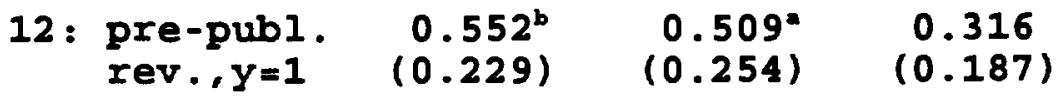

CONTROL VARS.

$\begin{array}{lcr}24: \text { space sci. } \quad- & 0.118 & 0.524^{*} \\ 1 \text {;geoph. } 2 & (0.226) & (0.248)\end{array}$

$\begin{array}{lllll}\text { Adjusted } R^{2} & 0.71^{\circ} & 0.68^{\mathrm{b}} & 0.67^{\circ} & 0.22^{\text {* }}\end{array}$

Notes: Standard errors are in parentheses below coefficients. $\operatorname{Prob}(\mid t$-statistic| $>x): a<.1, b<.05, c<.01, d<.001$. 
Table 6

Predictors of High-Valued Science

Dependent variable: 23--1 if respondents report major discoveries and interesting results and high overall success; 0 otherwise

Ind. Variables

Models

Model 1 Model 2 Model 3 Model 4 Model 5

Constant

$\begin{array}{rrrrr}4.778^{\circ} & 2.774^{b} & 2.711^{b} & 2.826^{\circ} & 1.208^{\circ} \\ (0.970) & (1.117) & (1.036) & (0.852) & (0.382)\end{array}$

ENDOWMENT

Conc, of Control

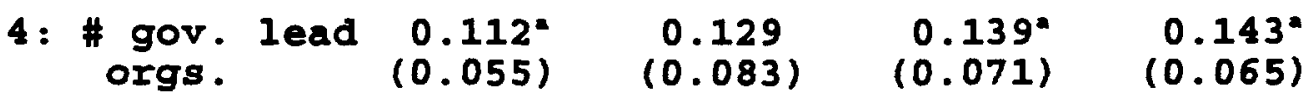

SOC. CONST. OF

TRUST-PRODUCING

SOC. STRUCTURE

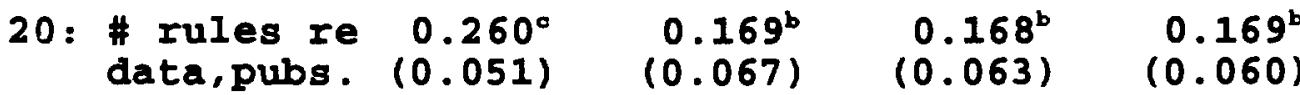

21: collegi- $-0.200 \quad 0.032$

ality $\quad(0.118) \quad(0.114)$

22: strong PI 0.001

control rts. $(0.172)$

CONTROL VARS.

\begin{tabular}{|c|c|c|c|c|c|c|}
\hline $24:$ & $\begin{array}{l}\text { space sci. } \\
1 \text {;geoph. } 2\end{array}$ & $\begin{array}{c}0.311 \\
(0.198)\end{array}$ & $\begin{array}{l}-0.027 \\
(0.262)\end{array}$ & $\begin{array}{l}-0.052 \\
(0.235)\end{array}$ & - & $\begin{array}{c}-0.542^{b} \\
(0.232)\end{array}$ \\
\hline & $\begin{array}{l}\text { year \$s } \\
\text { began }\end{array}$ & $\begin{array}{l}-0.068^{c} \\
(0.016)\end{array}$ & $\begin{array}{c}-0.040^{\circ} \\
(0.019)\end{array}$ & $\begin{array}{c}-0.038^{b} \\
(0.016)\end{array}$ & $\begin{array}{c}-0.041^{\circ} \\
(0.011)\end{array}$ & - \\
\hline & ted $\mathbf{R}^{2}$ & $0.85^{\circ}$ & $0.64^{\mathrm{b}}$ & $0.68^{\circ}$ & $0.71^{\circ}$ & $0.26^{b}$ \\
\hline
\end{tabular}

Notes: Standard errors are in parentheses below coefficients. Prob ( $|t-s t a t i s t i c|>x): a<.1, b<.05, c<.01, d<.001$. 
Table A

Predictors of Number of AIP Interviews

(Check for selectivity Bias)

Dependent variable: 26--number of AIP interviews

Ind. Vars. Models

Model 1 Model 2 Model 3 Model 4 Model 5 Model 6

Constant
$4.692^{\circ}$
3.049
$5.011^{b}$
4.253
$4.031 \quad 18.917^{d}$
(2.352)
(1.946)
(2.098)
(4.748)
(4.096) (3.107)

1: \# dif.

$0.442^{\circ}$

$0.450^{\circ}$

disciplns.

$(0.201)$

$(0.214)$

3 : \# Iead orgs.

0.101

8: \# all $\begin{aligned} & \text { orgs. } \\ & \text { org }\end{aligned}$

$(0.234)$

$0.339^{b}$
$(0.110)$

$0.301^{\circ}$

$0.323^{\circ}$

$0.369^{\circ}$

$0.294^{c}$

17: intl.ins. 3.044

$(0.079)$

$(0.086)$

$(0.093)$

$(0.088)$

construc.

$2.838^{b} \quad 1.941$

(1.523)

3.186

2.453

instrument

excit. des.

2.163

(1.504)

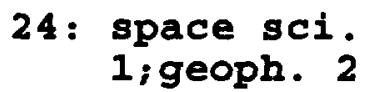

Adjusted $\mathbf{R}^{2}$

$0.60^{c}$

$0.73^{d}$

$0.66^{c}$

$\begin{array}{cc}0.054 & -0.472 \\ (1.956) & (1.705)\end{array}$

$-3.083$

Notes: Standard errors are in parentheses below coefficients. Prob (|t-statistic| $>x): a<.1, b<.05, c<.01, d<.001$. 
Figure 1. Scientific Collaborations in Space Science and Geophysics Selected for American Institute of Physics Project

Experiment name (acronym)

Active Magnetospheric Particle Tracer Experiment (AMPTE)

Consortium for Continental Reflection Profiling (COCORP)

Ocean Drilling Program, Leg 133 (ODP133)

EINSTEIN (Second High Energy Astrophysical Observatory

[HEAO-2])

\section{GIOTTO}

Greenland Ice Sheet Project (GISP2)

International Satellite Cloud Climatology Project (ISCCP)

International Sun-Earth Explorer 1-2 (ISEE1-2)
Area $^{2}$ Description

Space Three spacecraft performed coordinated functions with one another. The German spacecraft, together with a complementary set of instruments on the British spacecraft, orbited outside earth's magnetosphere and released tracer ions into the solar wind, while inside the magnetosphere the American spacecraft attempted to detect the released ions.

$\mathrm{C} / \mathrm{T}$ Examine sub-surface geology via adaption of commercial technology of seismic reflection profiling.

Ocean Retrieves cores from the ocean floor. Leg 133 explored Australia's Great Barrier Reef.

Space Obtained data on significant fixed $x$-ray sources by designing and building a spacecraft fitted with a $\mathrm{x}$-ray telescope and four instruments of varying resolutions and sensitivities to rotate into the telescope's focus.

Space Designed to study Halley's Comet's structure, composition, and environment; European Space Agency (ESA) spacecraft passed within 600 kilometers of the comet's nucleus.

$\mathrm{C} / \mathrm{T}$ Drilled a 5.2" ice core to 3000 meters in glacier; collaborative with European counterpart GRIP who won the "race" in obtaining ice core samples first just 39 kilometers away.

$\mathrm{C} / \mathrm{T}$ Sampled and processed cloud-radiation feedback and funded algorithm development to capture cloud characteristics against a global set of backgrounds.

Space Designed to resolve space-time ambiguities intrinsic to one-satellite examinations of the magnetosphere and its boundaries, two satellites shared a highly elliptical orbit and carried overlapping instrument packages (ISEE1 built by NASA and ISEE2 built by ESA) while a third in halo orbit a million miles from earth studied the solar wind before it reached 1 and 2 . 
Incorporated Research Institutes for Seismology (IRIS)

International Ultraviolet Explorer (IUE)

Parkfield Earthquake Prediction Experiment (PARKFIELD)

\section{VOYAGER}

Warm Core Rings (WCR)

World Ocean Circulation Experiment (WOCE)
C/T Digital technology, broad band access for academic seismologists via the Global Seismic Network (GSN) and a lending program for portable digital seismometers (Nebeker 1995).

Space Satellite in geosynchronous orbit operating as an ultraviolet astronomical observatory, joint with U.S.,U.K., and ESA.

$\mathrm{C} / \mathrm{T}$ Designed to acquire data on geophysical events and processes preceding an earthquake; predicted 6.0 or greater prior to 1993 at Parkfield. Earthquake did not occur.

Space Designed to collect planetary data, two interplanetary spacecraft took advantage of a rare planetary configuration in which the gravitation of each planet served to boost the spacecraft to the next. Out of ten experiment teams, focus on four instrument teams that had to coordinate data-taking because all bolted to a single scan platform.

Ocean Multiple ships, with satellite tracking also, to coordinate samples repeatedly of selected meso-scale eddies that separate from the Gulf Stream off eastern U.S. coast.

Ocean Measurement of world ocean circulation, focussing on a hydrographic survey of the Pacific Ocean and the Indian Ocean.

Note: $\quad$ Space $=$ Space Science $; \mathrm{C} / \mathrm{T}=$ Climate or Tectonics; Ocean $=$ Oceanography. Geophysics $=\mathrm{C} / \mathrm{T}+\mathrm{Ocean}$. 
Figure 2. The Endowed Supply of and Demand for Trust-Producing Social Structure in Scientific Collaborations in Physics

\section{COMPONENTS OF INITIAL ENDOWMENT}

A. CULTURAL HOMOGENEITY

- Trained in same discipline

(DeSantis 1980; Larson 1977)

- Few review boards (select and monitor PI proposals that form the collaboration), indicating high consensus on quality judgments

(Eccles and Crane 1988, Ch. 7-8; Zucker 1991; Zuckerman and Merton 1971)

B. ADMINISTRATIVE OVERSIGHT (THIRD-PARTY STRUCTURE AND ENFORCEMENT)

- Trust-producing social structure imported via control by an organization with legitimate control rights (Sayles and Chandler 1971, Ch. 4-5; Zucker 1986 on organizational intermediaries that are trusted)

- Located in the same organization (Zucker, Darby, Brewer, and Peng 1995; Darby and Karni 1973; Klein, Crawford, and Alchian 1978; Brewer and Silver 1978)

\section{FACTORS AFFECTING DEMAND}

A. DISRUPTION OF TRUST

- Conflict over professional standards/judgements (Tolbert 1988; Larson 1977)

B. COORDINATION REQUIREMENTS

- Coordination across projects within the collaboration increases the opportunity for opportunistic behavior (Klein 1988; Eccles 1981)

C. EXPECTED SCIENTIFIC VALUE

- Potential gains to others from opportunistic behavior are higher where the project is expected to have high scientific value

(Aghion and Tirole 1994, Zucker, Darby, Brewer, and Peng 1995)

\title{
SOCIAL CONSTRUCTION OF NEW SOCIAL STRUCTURE DESIGNED TO PRODUCE TRUST
}

\author{
FORMAL RULES \\ (Zucker 1986; Tolbert 1988; Eisenberg 1987) \\ COLLEGIALITY \\ (Eccles and Crane 1988; Zucker 1991) \\ PRINCIPAL INVESTIGATOR CONTROL RIGHTS \\ (Eisenberg 1987)
}




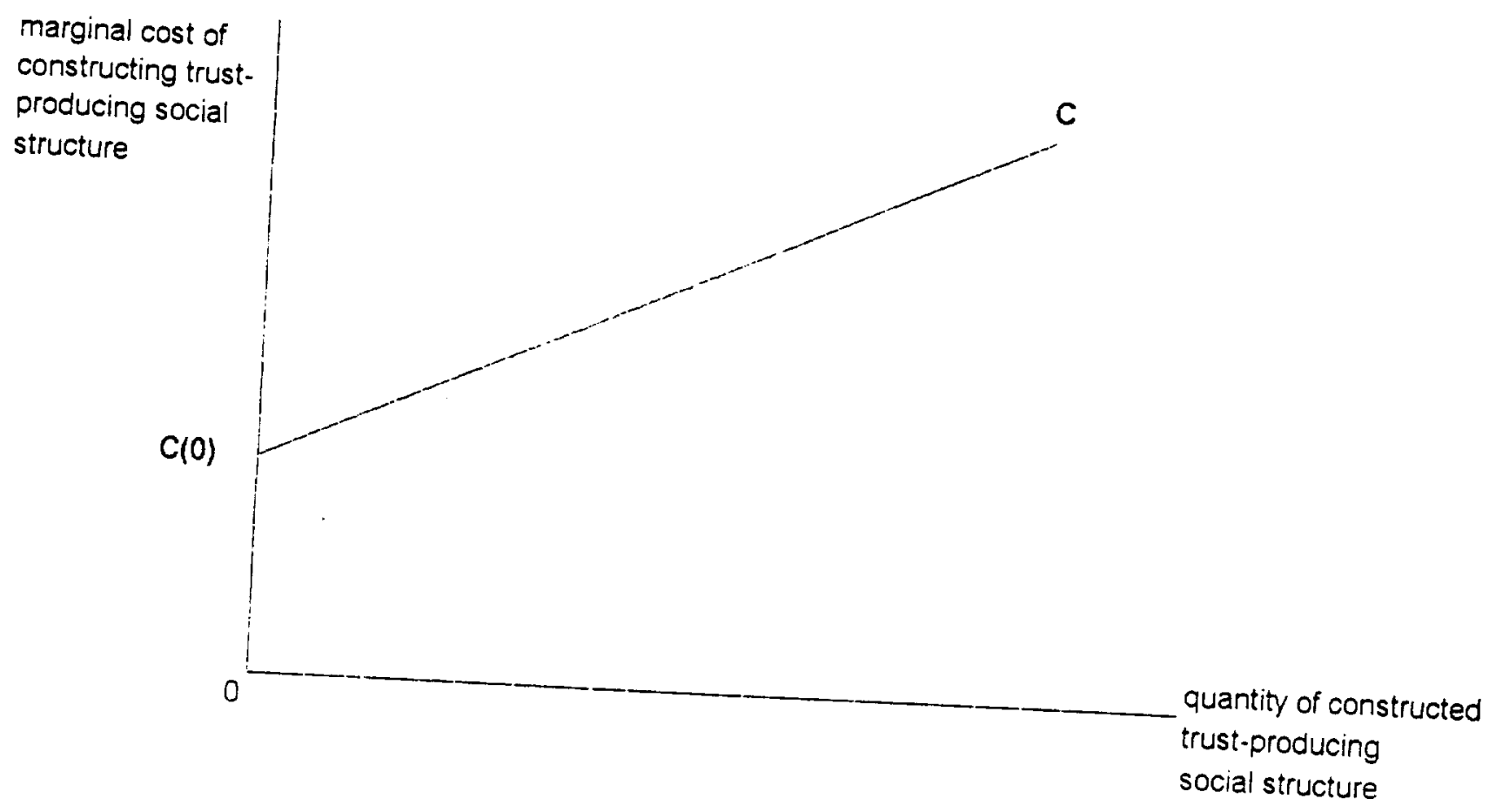

Figure 3
Cost Conditions for Construction of Trust-producing Social Structure 


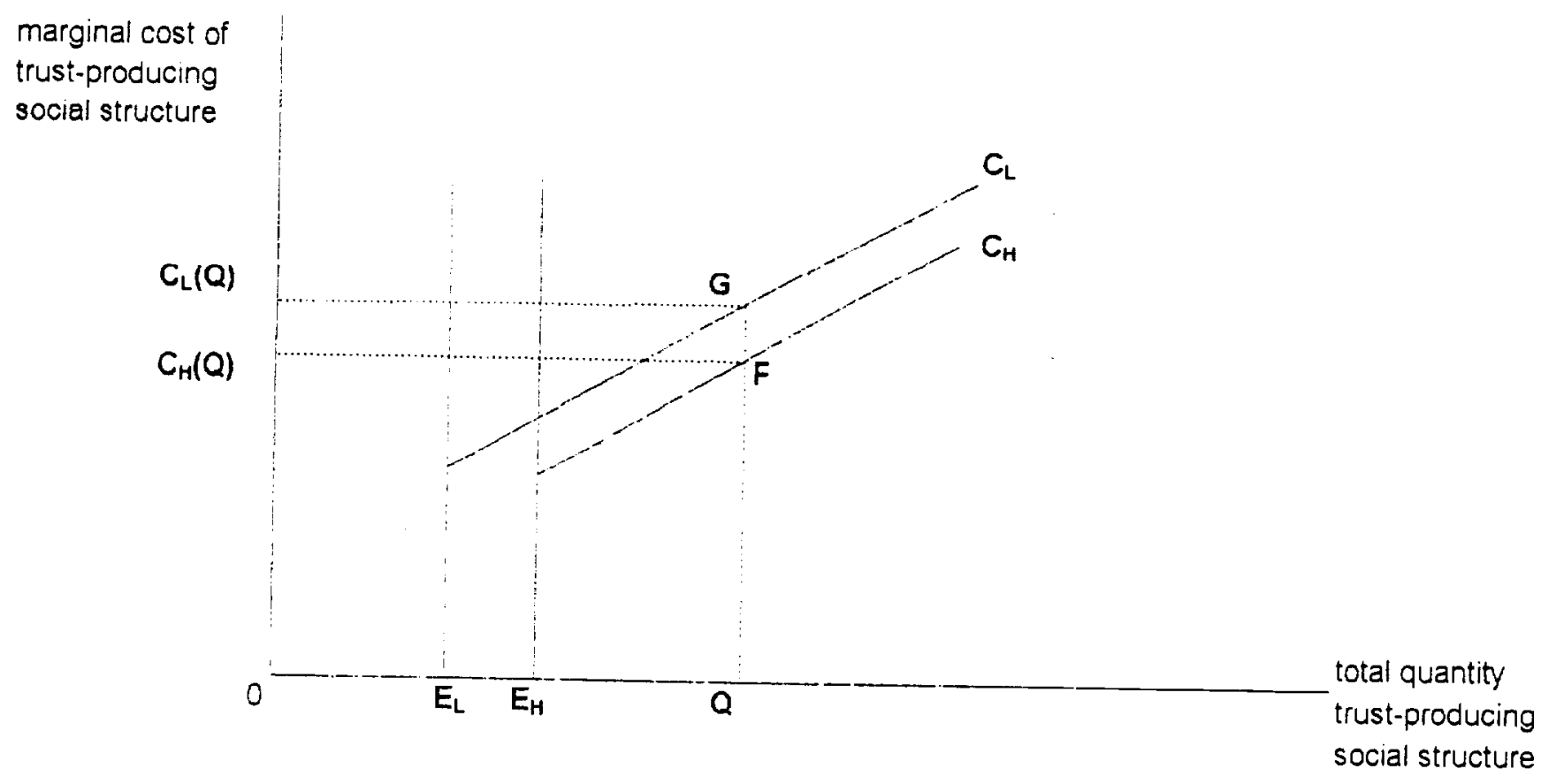

Figure 4

Cost Conditions for Total Quantity of Trust-producing Social Structure 


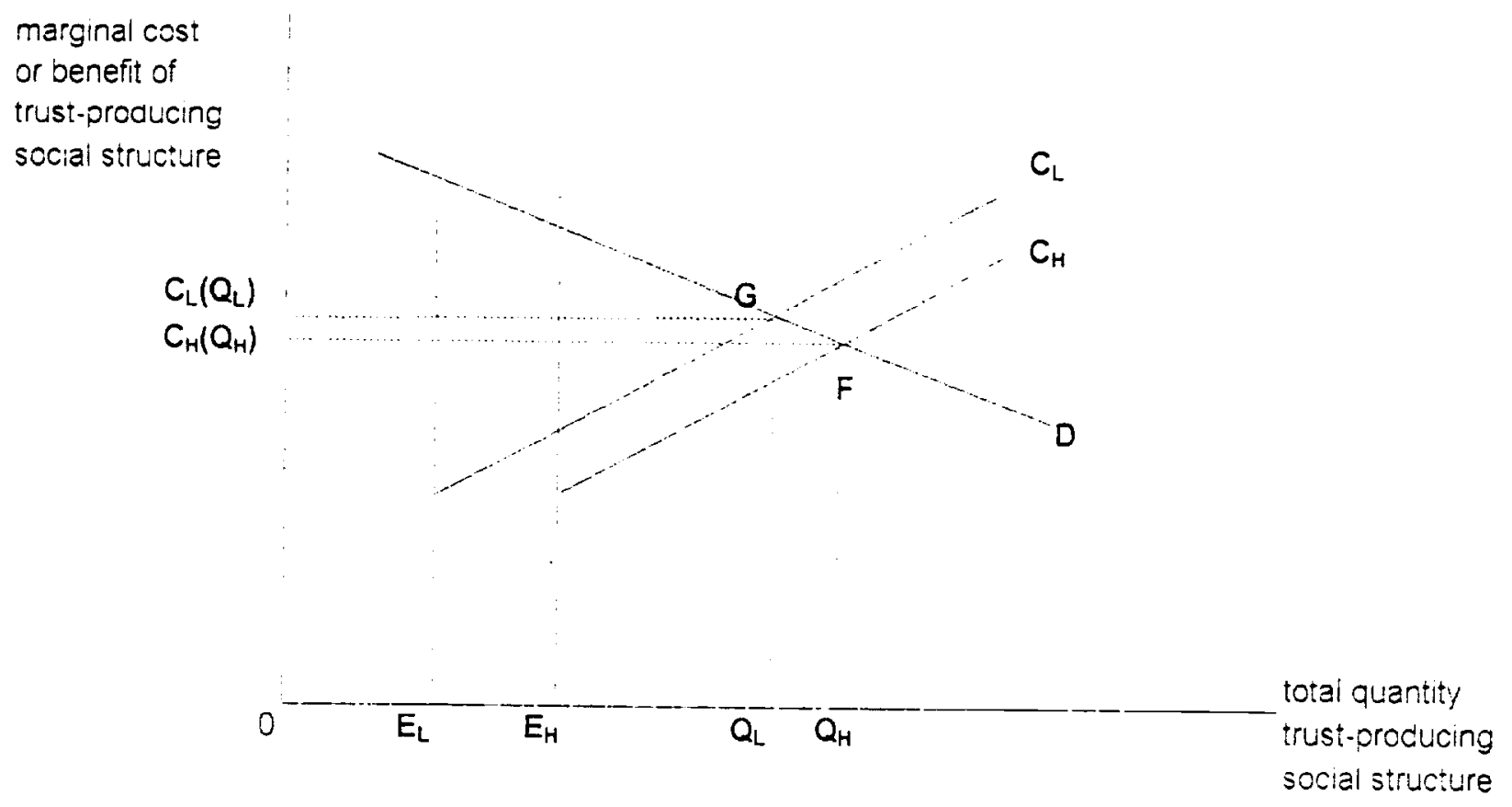

Figure 5

Equilibrium Social Structures with Different Endowments of Trust-producing Social Structure 


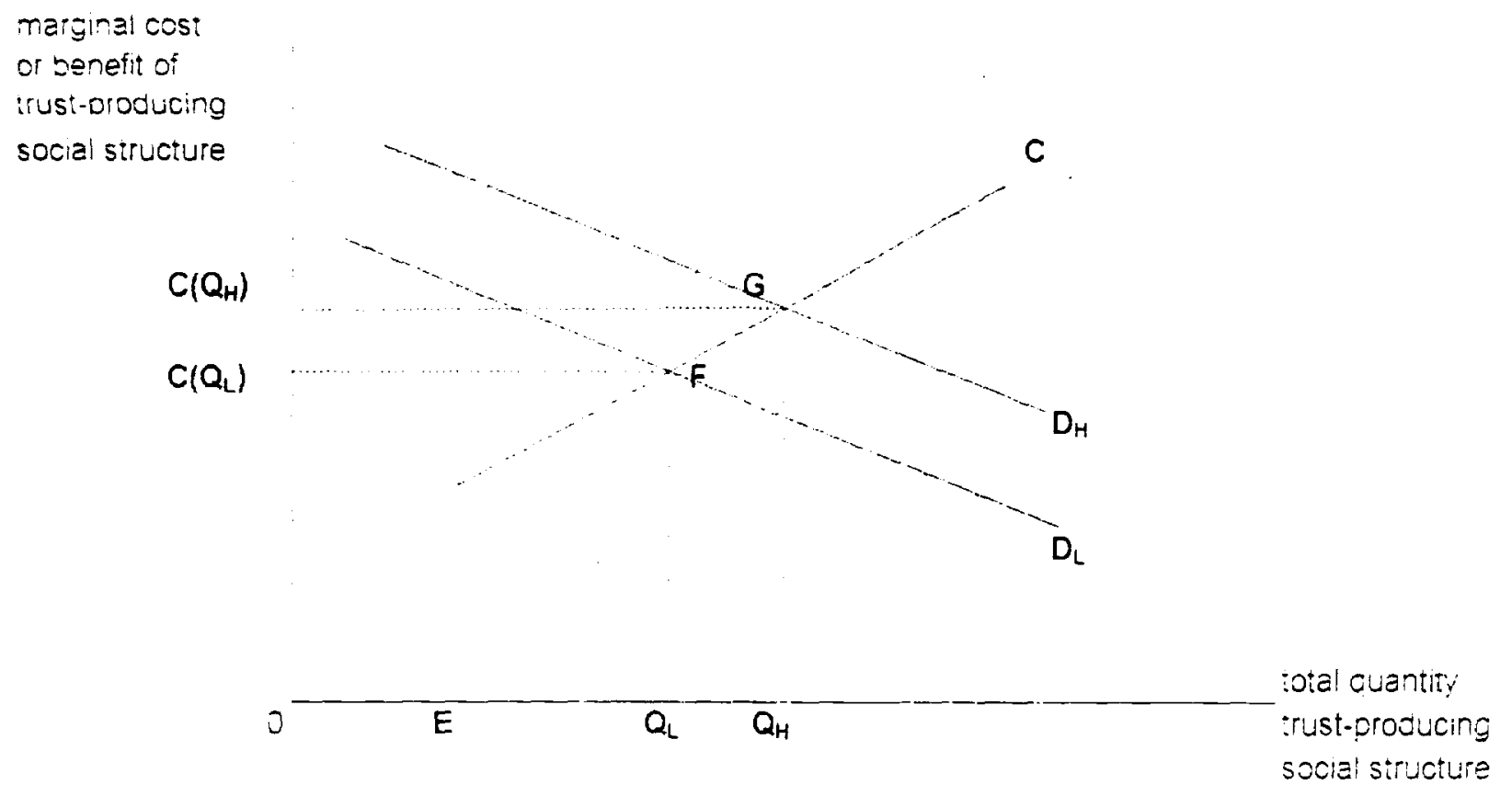

Figure 6

Equilibrium Social Structures with Different Demand for Trust-Producing Social Structures 